\section{Associação entre peso ao nascer e o excesso de peso na infância: revisão sistemática}

\author{
Birth weight and overweight in childhood: \\ a systematic review
}

\author{
1 Escola Nacional de Saúde \\ Pública Sergio Arouca, \\ Fundação Oswaldo Cruz, \\ Rio de Janeiro, Brasil. \\ 2 Faculdade de Nutrição, \\ Universidade Federal de \\ Pelotas, Pelotas, Brasil. \\ Correspondência \\ E. B. Martins \\ Departamento de \\ Epidemiologia e Métodos \\ Quantitativos em Saúde, \\ Escola Nacional de Saúde \\ Pública Sergio Arouca, \\ Fundação Oswaldo Cruz. \\ Rua Leopoldo Bulhões 1480 , \\ Rio de Janeiro, $R J$ \\ 21041-210, Brasil. \\ elianab@ensp.fiocruz.br
}

\begin{abstract}
Birth weight is associated with overweight and obesity in childhood. However, results are controversial. The aim of this systematic review is to identify concordant and contradictory aspects on the association between birth weight and overweight in children up to seven years of age. The first eight articles were selected in a previous review evaluating risk factors for childhood obesity. The search in PubMed between 1993 and 2004, using keywords "birth weight AND childhood", "obesity" and "overweight", together with the previous ones added up to 20 papers conforming the review criteria. Despite the studies' heterogeneity, a positive association between birth weight and some kind of childhood obesity was predominant among the published papers. Meanwhile, the inconsistency of some aspects related to birth weight and childhood obesity suggests the need for an approach allowing the inclusion of some context effects on the childhood obesity risk factors framework.
\end{abstract}

Birth Weight; Obesity; Child Welfare; Risk Factors; Review [Publication Type]
Eliana Bender Martins 1,2 Marília Sá Carvalho ${ }^{1}$

\section{Introdução}

As modificações no perfil nutricional das populações nas últimas décadas têm se caracterizado pelo aumento da obesidade e redução nas prevalências de desnutrição entre adultos e crianças com a ocorrência simultânea de ambas em regiões em desenvolvimento 1 . Além de promover distúrbios na esfera psicossocial durante a infância e adolescência, estudos têm sugerido uma associação entre a obesidade na infância e na vida adulta e maior risco para doenças crônicas não transmissíveis 2,3. Diversos fatores têm sido associados a esse fenômeno, entre esses, o peso ao nascer, tornando-o um dos mais importantes temas da Saúde Pública da atualidade. Contudo, apesar de um grande número de publicações evidenciar uma associação predominantemente positiva entre o peso ao nascer e o excesso de peso na infância, não foi possível estimar, em uma única medida, o quanto o peso ao nascer contribui para o surgimento do sobrepeso e/ou obesidade, seja pelas várias definições atribuídas ao excesso de peso pelos diferentes desenhos utilizados ou às limitações relacionadas aos métodos de análise empregados. O objetivo principal desta revisão é identificar pontos concordantes e inconsistentes nos artigos que analisaram a associação entre o peso ao nascer e o excesso de peso na infância. Dentre os aspectos a serem analisados, incluem-se: critérios adotados para definir 
peso ao nascer, sobrepeso e/ou obesidade, desenhos de estudos, co-variáveis e medidas de efeito utilizadas na análise, entre outros itens.

\section{Peso ao nascer e sua associação com a obesidade e sobrepeso na infância}

Cinco artigos de revisão incluíram o peso ao nascer dentre outros fatores associados com o sobrepeso e/ou obesidade na infância.

Na revisão sistemática de Parsons et al. 2, que incluiu estudos predominantemente longitudinais, foram encontradas evidências de uma associação positiva entre o peso ao nascer com a obesidade em crianças menores de sete anos, porém poucos abordaram potenciais variáveis de confusão como idade gestacional, obesidade dos pais e situação sócio-econômica. Um dos estudos revisados por aquele autor mostrou um efeito não linear do peso ao nascer. Crianças que nasceram com baixo peso também tiveram um maior risco de adquirir obesidade na infância, ainda que esse risco fosse maior para as crianças que nasceram com peso elevado.

Livingstone 4 enfatizou o Índice de Massa Corporal (IMC) dos pais e, em menor extensão, o peso ao nascer como os fatores mais consistentemente associados com a adiposidade nas crianças, destacando a inconsistência dos achados relacionados aos aspectos ambientais.

Na revisão apresentada por Martorell et al. 5, que investigou a influência de fatores nutricionais durante a gestação e nos três primeiros anos de vida no desenvolvimento da obesidade em adultos e adolescentes, foram observadas associações não lineares entre o peso ao nascer e o IMC. Alguns estudos apresentaram uma associação na forma de J ou U para o IMC. Crianças nascidas com baixo peso também apresentaram risco para obesidade quando adultos, ainda que esse risco fosse maior para os nascidos de peso elevado, quando comparados aos nascidos com peso mediano. As evidências de risco para o baixo peso ao nascer e para a restrição do crescimento intra-uterino no desenvolvimento de obesidade em adolescentes ou adultos foram inconsistentes. Quanto ao elevado peso ao nascer, as evidências de associação positiva com a obesidade foram consistentes apenas para os países desenvolvidos.

Em uma recente revisão ${ }^{6}$, que avaliou especificamente a influência do peso ao nascer e do ambiente intra-uterino na obesidade e distribuição de tecido adiposo entre crianças e adolescentes, foram encontradas evidências consistentes de associação com o IMC de ambos os grupos. Dentre os estudos incluídos na revisão, encontram-se aqueles que mostraram uma relação linear e positiva entre o peso ao nascer e o IMC e os estudos que não encontraram associação entre o baixo peso ao nascer $(<2.500 \mathrm{~g})$ e o IMC na adolescência. Uma associação não linear, porém em forma de J ou U entre o peso ao nascer e o IMC, também foi referida nesta revisão.

A mais recente e ampla revisão 7 sobre obesidade na infância e adolescência referiu um grande número de estudos que mostraram associação positiva entre o peso ao nascer e subseqüente obesidade, salientando o papel preponderante do ambiente intra-útero.

A obesidade dos pais, principalmente a materna, seria um preditor importante para a obesidade infantil, independente do peso ao nascer, idade gestacional e da situação sócio-econômica, destacando também a relação não linear entre o crescimento intra-uterino e a obesidade encontrada em alguns estudos.

Além desses, a revisão 7 cita a influência do rápido crescimento durante os quatro primeiros meses de vida no desenvolvimento de obesidade aos sete anos, independente do peso ao nascer, da idade gestacional, do peso à idade de um ano, do IMC e do nível educacional materno. Já outros estudos dessa mesma revisão verificaram o efeito do crescimento rápido decorrente da restrição do crescimento intra-uterino no risco da obesidade (catch-up).

Quanto ao baixo peso ao nascer, foram encontradas evidências de uma associação positiva com o déficit de peso para estatura (stunting), obesidade abdominal e síndrome metabólica.

Em resumo, das revisões acima, podem ser destacados seis aspectos do peso ao nascer e sua associação com a obesidade infantil:

- Associação positiva na qual as crianças que nascem com peso mais elevado têm maior probabilidade de apresentar obesidade na infância, e, portanto, o baixo peso ao nascer atuaria como um fator protetor;

- O baixo peso ao nascer não teria nenhuma influência no surgimento da obesidade na infância, porém crianças que nascem com restrição do crescimento intra-uterino estariam mais propensas a serem obesas na infância;

- Ausência de associação entre restrição do crescimento intra-uterino e obesidade: as crianças que nascem com restrição do crescimento intra-uterino não teriam maiores chances de apresentar obesidade;

- Associação não linear: tanto crianças que nascem com baixo peso como aquelas que nascem com peso elevado têm probabilidade de apresentar obesidade na infância, sendo essa maior para aquelas que nascem com maior peso; 
- Associação entre o baixo peso e/ou retardo do crescimento intra-uterino e obesidade intermediada pelo rápido crescimento: crianças que nascem com baixo peso ou com retardo no crescimento intra-uterino crescem mais rapidamente durante os primeiros anos (catch-up) e estão mais sujeitas ao risco de obesidade comparadas àquelas que nascem com peso adequado (hipótese pré-natal);

- Ausência de associação entre o peso ao nascer e a obesidade na infância. Esta poderia ser determinada pelo crescimento acelerado durante a infância, independente do peso ao nascer (hipótese pós-natal).

\section{Metodologia}

O presente trabalho teve início em uma revisão sistemática anterior cujo objetivo foi identificar fatores de risco para obesidade infantil, uma vez que se pretendia, a princípio, ter uma visão geral dos principais fatores determinantes da obesidade na infância. As bases de dados utilizadas para aquele levantamento foram MEDLINE, Web of Science, Human Nutrition, ADOLEC, MedCaribe e LILACS. As palavraschaves empregadas foram: "obesity AND child malnutrition"; "overweight AND malnutrition AND child". Dos 285 artigos inicialmente rastreados que identificaram fatores de risco para a obesidade infantil, foram selecionados 122 artigos publicados em inglês entre 1993 e 2003 que possuíam objetivos claramente definidos quanto aos fatores de risco para obesidade na infância e que incluíram crianças de até sete anos de idade. Posteriormente, foram excluídos os artigos que enfocaram crianças portadoras de patologias ou que se restringiram à discussão de critérios para definir obesidade ou abordavam o tratamento ou avaliação bioquímica da obesidade, além dos artigos cuja variável de desfecho não era obesidade infantil. Um total de 24 artigos descreveu algum tipo de associação entre a obesidade infantil e um ou mais fatores de risco.

Para o presente estudo, foram inicialmente selecionados oito artigos da revisão anterior que analisaram a associação entre o peso ao nascer e o sobrepeso e/ou obesidade na infância $8,9,10,11,12,13,14,15$. A seguir, outros seis artigos $16,17,18,19,20,21$ foram adicionados a esta revisão, identificados pela lista de referência ou por sugestão de pesquisadores. Posteriormente, nova busca bibliográfica foi realizada com as palavraschaves: "birth weight"; " birthweight"; "childhood"; "child preschool AND obesity"; "overweight", através da biblioteca PubMed, via Na- tional Library of Medicine, com o auxílio do programa End Note, sendo rastreados, inicialmente, 198 artigos com data entre 1993 e 2004. Desses, foram selecionados apenas os artigos publicados em inglês que atenderam aos seguintes critérios de inclusão/exclusão: ter objetivos claramente definidos, incluir recém-nascidos e crianças menores de um ano e/ou de 1 a 7 anos, possuir desenho do estudo definido, apresentar definição dos indicadores utilizados para medir excesso de peso (sobrepeso/obesidade), descrever co-variáveis sócio-econômicas, biológicas, dietéticas e antropométricas, considerar outros fatores de risco na análise dos resultados, descrever a magnitude e o tipo de associação encontrada entre o peso ao nascer e o excesso de peso.

Foram considerados irrelevantes os artigos identificados com alguma(s) das seguintes características: amostras representativas de uma população muito específica (hospitais, clínicas, população indígena, beneficiários de programa de suplementação alimentar), crianças portadoras de patologias, estudos sem afinidade com o tema descrito no resumo, estudos de intervenção, hormonais ou sobre preditores genéticos da obesidade, com enfoque em critérios de comparação ou validação de medidas, com outros desfechos como asma, pressão arterial, artrite, síndrome metabólica dos pais, estudos que avaliaram associações a partir da faixa etária de sete anos, sem informação sobre a magnitude e o tipo de associação encontrada para peso ao nascer e excesso de peso, estudos cujo fator de exposição esteve relacionado a alguma patologia como o diabetes gestacional e artigos narrativos ou de revisão.

O limite da idade até sete anos, detectado pela leitura do artigo quando esse não era apresentado no resumo, e a observação dos critérios de inclusão/exclusão descritos anteriormente definiram a seleção de mais seis artigos 22,23, $24,25,26,27$ após a exclusão das duplicatas. Ao todo, 20 artigos foram analisados em profundidade (Figura 1).

Para avaliar a qualidade dos artigos, adotouse a metodologia proposta por Downs \& Black 28, para estudos observacionais. Esse instrumento tem o objetivo de orientar revisores na identificação das características metodológicas mais relevantes em estudos observacionais. Esse procedimento foi utilizado em outros trabalhos, com adaptações do método original 16,29. Os itens propostos avaliam clareza da redação (nove itens), validade externa (dois itens), validade interna (sete itens), fatores de confusão (quatro itens) e poder do estudo (um item). A pontuação máxima possível para cada artigo foi de 24 . 
Objetivos indefinidos Foco: desnutrição Faixa etária $>7$ anos Portadores de patologias Foco: critérios e padrões para definir obesidade, tratamento e bioquímica, grupos populacionais específicos. Outros desfechos (asma, hipertensão) Artigos de revisão

98 artigos excluídos

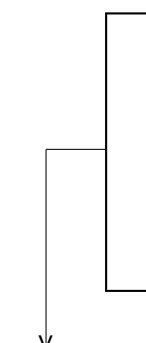

Outros desfechos: 3

Populações específicas: participantes de 1 programa de suplementação alimentar: 1 Comunidade rural: 1

Faixa etária acima de 7 anos: 8 Sem informação de resultados para peso ao nascer: 6 Artigos de revisão: 2

Artigos não disponíveis na íntegra: 2 Duplicatas: 15

Total de excluídos: 16 artigos
PRIMEIRA REVISÃO

Obesity AND Child Malnutrition Overweight AND Malnutrition AND Child

- PubMed/Adolec/LILACS -1993 a 2003

- 285 artigos rastreados,

122 potencialmente elegíveis

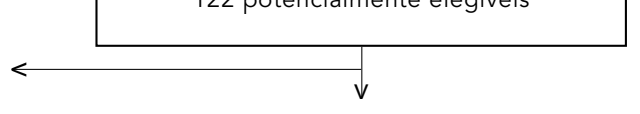

FATORES DE RISCO PARA OBESIDADE

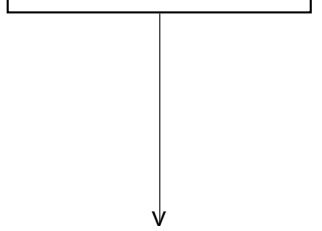

- 198 artigos rastreados 38 potencialmente elegíveis

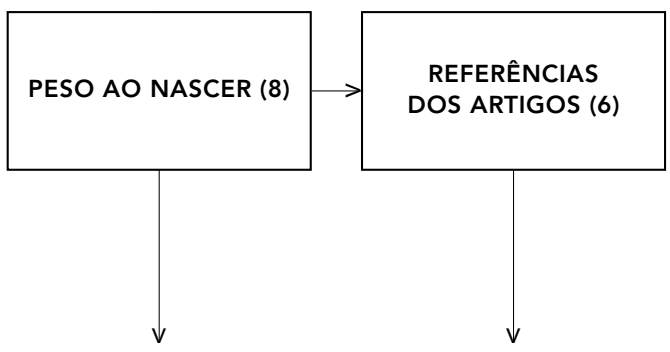

ASSOCIACCÃO ENTRE PESO AO NASCER E EXCESSO DE PESO NA INFÂNCIA. TOTAL: 20 ARTIGOS

Nota: entre parênteses o número de artigos em cada etapa assinalada.

\section{Resultados}

Um total de vinte artigos descreveu a associação entre o peso ao nascer e o sobrepeso e /ou obesidade na infância.

A Tabela 1 sumariza os aspectos gerais dos estudos, e a Tabela 2 apresenta os escores e os aspectos específicos das associações encontradas.

Dentre os estudos que tinham por objetivo avaliar o efeito do peso ao nascer no sobrepeso/obesidade na infância, quatro se propuseram a avaliar também o crescimento durante a infância 16,17,19,23.

O efeito das mudanças no peso para altura e no IMC foi objeto de outro estudo que com- parou crianças de diferentes raças e etnias 25 . Já um outro estudo que utilizou a mesma fonte de dados do estudo anterior avaliou a contribuição do peso ao nascer nos tipos de adiposidade subcutânea considerando as diferenças étnicas e raciais 22 .

Outros dois estudos avaliaram o ganho de peso como variável de desfecho, um deles investigou o efeito da associação entre o IMC prégestacional e o padrão de aleitamento materno no aumento do peso até um ano ${ }^{30}$, e o outro avaliou a associação entre o ganho de peso até os quatro anos de idade e o sobrepeso aos sete anos 20. Os demais estudos tiveram por objetivo analisar outros determinantes da obesidade 
Características dos estudos com associação entre peso ao nascer e obesidade na infância, de acordo com o desenho utilizado, $1993 / 2003$.

\begin{tabular}{|c|c|c|c|c|c|c|c|}
\hline Referência & Ano & Local & Desenho & $\begin{array}{l}\text { Número de } \\
\text { sujeitos }\end{array}$ & Fonte & Idade & Objetivos \\
\hline Baker et al. 30 & 2004 & Dinamarca & $\begin{array}{l}\text { Longitudinal } \\
\text { prospectivo }\end{array}$ & 3.768 & $\begin{array}{l}\text { Estudo Longitudinal } \\
\text { de Nascimentos da } \\
\text { Dinamarca de } 1996\end{array}$ & 0-18 meses & $\begin{array}{l}\text { Avaliar a associação entre o } \\
\text { IMC }\left(\mathrm{Kg} / \mathrm{m}^{2}\right) \text { pré-gestacional } \\
\text { e o padrão de aleitamento } \\
\text { materno no ganho de peso } \\
\text { desde o nascimento até } \\
1 \text { ano de idade }\end{array}$ \\
\hline $\begin{array}{l}\text { Eriksson } \\
\text { et al. } 17\end{array}$ & 2001 & Finlândia & $\begin{array}{l}\text { Longitudinal } \\
\text { prospectivo }\end{array}$ & $\begin{array}{l}1.552 \text { homens e } \\
2.107 \text { mulheres } \\
\text { nascidos entre } \\
1924 \text { e } 1933\end{array}$ & $\begin{array}{l}\text { Nascimentos } \\
\text { hospitalares das } \\
\text { crianças que } \\
\text { freqüentaram as } \\
\text { escolas na cidade } \\
\text { de Helsinque e que } \\
\text { eram residentes na } \\
\text { Finlândia em } 1971\end{array}$ & $\begin{array}{l}\text { Ao nascer, aos } 7 \\
\text { e aos } 15 \text { anos } \\
\text { e adultos }\end{array}$ & $\begin{array}{l}\text { Avaliar a associação entre } \\
\text { obesidade, o tamanho ao } \\
\text { nascer e o crescimento } \\
\text { durante a infância }\end{array}$ \\
\hline Ong et al. 19 & 2000 & $\begin{array}{l}\text { Reino } \\
\text { Unido }\end{array}$ & $\begin{array}{l}\text { Longitudinal } \\
\text { prospectivo }\end{array}$ & $\begin{array}{l}848 \text { avaliados } \\
\text { ao nascer, aos } \\
2 \text { e } 5 \text { anos }\end{array}$ & Base populacional & $\begin{array}{l}\text { Ao nascer, aos } \\
2 \text { anos e aos } \\
5 \text { anos }\end{array}$ & $\begin{array}{l}\text { Identificar preditores do } \\
\text { crescimento acelerado pós- } \\
\text { natal desde o nascimento } \\
\text { até os } 2 \text { anos e sua } \\
\text { associação com tamanho } \\
\text { e obesidade aos } 5 \text { anos }\end{array}$ \\
\hline $\begin{array}{l}\text { Stettler } \\
\text { et al. } 20\end{array}$ & 2002 & $\begin{array}{l}\text { Estados } \\
\text { Unidos }\end{array}$ & $\begin{array}{l}\text { Longitudinal } \\
\text { prospectivo }\end{array}$ & $\begin{array}{l}19.937 \text { indivíduos } \\
\text { de } 20 \text { localidades } \\
\text { dos Estados } \\
\text { Unidos, entre } \\
1959 \text { e } 1965\end{array}$ & $\begin{array}{l}\text { Participantes do } \\
\text { National } \\
\text { Collaborative } \\
\text { Perinatal Project } \\
\text { (CPP) }\end{array}$ & $\begin{array}{l}\text { Ao nascer, aos } \\
4 \text { meses e aos } \\
7 \text { anos }\end{array}$ & $\begin{array}{l}\text { Avaliar a associação entre o } \\
\text { rápido ganho de peso no } \\
\text { primeiro ano de vida e o } \\
\text { sobrepeso aos } 7 \text { anos }\end{array}$ \\
\hline Whitaker 18 & 2004 & $\begin{array}{l}\text { Estados } \\
\text { Unidos }\end{array}$ & $\begin{array}{l}\text { Longitudinal } \\
\text { retrospectivo }\end{array}$ & $\begin{array}{l}8.494 \text { crianças } \\
\text { beneficiárias do } \\
\text { Programa de } \\
\text { Suplementação } \\
\text { Nutricional em } \\
\text { Ohio }\end{array}$ & $\begin{array}{l}\text { Special Supplemental } \\
\text { Program for Women, } \\
\text { Infants and Children } \\
\text { (WIC) }\end{array}$ & De 2 a 4 anos & $\begin{array}{l}\text { Comparar as prevalências } \\
\text { de obesidade entre filhos } \\
\text { de mães obesas e não } \\
\text { obesas durante a gestação }\end{array}$ \\
\hline $\begin{array}{l}\text { Danielzik } \\
\text { et al. } 24\end{array}$ & 2004 & Alemanha & Transversal & $\begin{array}{l}2.631 \text { estudantes } \\
\text { de } 32 \text { escolas } \\
\text { primárias na região } \\
\text { noroeste da } \\
\text { Alemanha }\end{array}$ & $\begin{array}{l}\text { Sub-coorte do Kiel } \\
\text { Obesity Prevention } \\
\text { Study (KOPS) }\end{array}$ & 5 a 7 anos & $\begin{array}{l}\text { Identificar os principais } \\
\text { fatores de risco para } \\
\text { sobrepeso e obesidade em } \\
\text { pré-adolescentes }\end{array}$ \\
\hline $\begin{array}{l}\text { Drachler } \\
\text { et al. } 8\end{array}$ & 2003 & Brasil & Transversal & 2.687 (perdas: 27) & $\begin{array}{l}\text { Inquérito sobre } \\
\text { desenvolvimento e } \\
\text { estado nutricional } \\
\text { em amostra repre- } \\
\text { sentativa de crianças } \\
\text { menores de cinco } \\
\text { anos de agosto de } \\
1988 \text { a junho de } 1990\end{array}$ & 1 a 5 anos & $\begin{array}{l}\text { Avaliar a associação entre } \\
\text { condições sócio-econômicas } \\
\text { e outros fatores com o } \\
\text { sobrepeso na infância }\end{array}$ \\
\hline
\end{tabular}

(continua) 
Tabela 1 (continuação)

\begin{tabular}{|c|c|c|c|c|c|c|c|}
\hline Referência & Ano & Local & Desenho & $\begin{array}{l}\text { Número de } \\
\text { sujeitos }\end{array}$ & Fonte & Idade & Objetivos \\
\hline $\begin{array}{l}\text { Frye \& } \\
\text { Heinrich } 13\end{array}$ & 2003 & Alemanha & $\begin{array}{l}\text { Transversal } \\
\text { consecutivo }\end{array}$ & $\begin{array}{l}6.650 \text { escolares } \\
\text { de } 3 \text { regiões do } \\
\text { anterior Leste da } \\
\text { Alemanha }\end{array}$ & $\begin{array}{l}\text { Inquéritos escolares } \\
\text { avaliados em três } \\
\text { períodos (1992-1993, } \\
\text { 1995-1996 e 1998- } \\
\text { 1999) e fazem parte } \\
\text { do estudo longitu- } \\
\text { dinal Bitterfeld que } \\
\text { avalia os efeitos da } \\
\text { poluição atmosférica }\end{array}$ & $\begin{array}{l}5 \text { a } 7,8 \text { a } 10 \text { e } \\
11 \text { a } 14 \text { anos }\end{array}$ & $\begin{array}{l}\text { Avaliar a tendência de } \\
\text { sobrepeso e obesidade em } \\
\text { escolares }\end{array}$ \\
\hline $\begin{array}{l}\text { Monteiro } \\
\text { et al. } 16\end{array}$ & 2003 & Brasil & $\begin{array}{l}\text { Transversal } \\
\text { aninhado em } \\
\text { longitudinal }\end{array}$ & 1.076 & $\begin{array}{l}\text { Base populacional: } \\
\text { nascimentos } \\
\text { ocorridos em } 1982 \\
\text { em Pelotas, Rio } \\
\text { Grande do Sul }\end{array}$ & $\begin{array}{l}\text { Ao nascer, aos } 20 \\
\text { e } 40 \text { meses e aos } \\
14 \text { e } 16 \text { anos }\end{array}$ & $\begin{array}{l}\text { Avaliar a associação entre o } \\
\text { peso e comprimento para } \\
\text { altura e a velocidade do } \\
\text { crescimento infantil com } \\
\text { sobrepeso e obesidade em } \\
\text { adolescentes }\end{array}$ \\
\hline $\begin{array}{l}\text { Okosun } \\
\text { et al. } 22\end{array}$ & 2000 & $\begin{array}{l}\text { Estados } \\
\text { Unidos }\end{array}$ & Transversal & 2.488 & $\begin{array}{l}\text { Third National } \\
\text { Health and Nutrition } \\
\text { Examination Survey } \\
1988-1994 \\
\text { (III NHANES) }\end{array}$ & 5 a 11 anos & $\begin{array}{l}\text { Avaliar a associação entre o } \\
\text { peso ao nascer e tipos de } \\
\text { adiposidade subcutânea em } \\
\text { crianças norte-americanas } \\
\text { de diferentes etnias }\end{array}$ \\
\hline $\begin{array}{l}\text { Overpeck } \\
\text { et al. } 25\end{array}$ & 2000 & $\begin{array}{l}\text { Estados } \\
\text { Unidos }\end{array}$ & $\begin{array}{l}\text { Transversal de } \\
\text { representativi- } \\
\text { dade nacional }\end{array}$ & $\begin{array}{l}6.226 \text { crianças } \\
\text { norte-americanas } \\
\text { brancas e negras } \\
\text { de origem não } \\
\text { hispânica ( } 2.492 \text { e } \\
\text { 1.620) e méxico- } \\
\text { americanas (1.753) } \\
\text { (perdas: } 777 \text { ) }\end{array}$ & $\begin{array}{l}\text { Third National } \\
\text { Health and Nutrition } \\
\text { Examination Survey } \\
1988-1994 \\
\text { (III NHANES) }\end{array}$ & $\begin{array}{l}2 \text { meses a } \\
6 \text { anos }\end{array}$ & $\begin{array}{l}\text { Comparar mudanças no } \\
\text { peso, altura e IMC na } \\
\text { infância com a prevalência } \\
\text { de obesidade em } \\
\text { adolescentes e adultos }\end{array}$ \\
\hline $\begin{array}{l}\text { Toschke } \\
\text { et al. } 14\end{array}$ & 2002 & Alemanha & Transversal & $\begin{array}{l}8.765 \\
\text { (perdas: 400) }\end{array}$ & $\begin{array}{l}\text { População de } \\
\text { escolares do Bavarian } \\
\text { Schoolentry Health } \\
\text { Examination }\end{array}$ & 5 a 6 anos & $\begin{array}{l}\text { Avaliar a associação entre } \\
\text { o hábito de fumar na } \\
\text { gestação e a obesidade } \\
\text { infantil }\end{array}$ \\
\hline $\begin{array}{l}\text { von Kries } \\
\text { et al. } 15\end{array}$ & 1999 & Alemanha & Transversal & $\begin{array}{l}9.357 \text { crianças } \\
\text { da região Sul } \\
\text { da Alemanha } \\
\text { (perdas: } 151 \text { ) }\end{array}$ & $\begin{array}{l}\text { População de } \\
\text { escolares do Bavarian } \\
\text { Schoolentry Health } \\
\text { Examination }\end{array}$ & 5 a 6 anos & $\begin{array}{l}\text { Avaliar o impacto do } \\
\text { aleitamento materno no } \\
\text { risco de sobrepeso e } \\
\text { obesidade infantil }\end{array}$ \\
\hline $\begin{array}{l}\text { von Kries } \\
\text { et al. } 27\end{array}$ & 2002 & Alemanha & Transversal & $\begin{array}{l}6.483 \\
\text { (perdas: 464) }\end{array}$ & $\begin{array}{l}\text { Unidades de saúde } \\
\text { pública de } 6 \text { comu- } \\
\text { nidades da Bavária } \\
\text { que participaram do } \\
\text { Bavarian Schoolentry } \\
\text { Health Examination } \\
\text { durante o período } \\
\text { de } 1999 \text { a } 2000\end{array}$ & 5 a 6 anos & $\begin{array}{l}\text { Avaliar o impacto de fumar } \\
\text { durante a gestação no risco } \\
\text { de sobrepeso e obesidade } \\
\text { infantil }\end{array}$ \\
\hline He et al. 9 & 2000 & China & $\begin{array}{l}\text { Caso-controle } \\
\text { nacional }\end{array}$ & $\begin{array}{l}1.322 \text {, sendo } \\
748 \text { meninos } \\
\text { e } 574 \text { meninas } \\
\text { (perdas: } 4 \% \text { ) }\end{array}$ & $\begin{array}{l}\text { Centro de saúde de } \\
8 \text { cidades chinesas }\end{array}$ & $\begin{array}{l}1 \text { mês a } 2,9 \text { anos; } \\
3 \text { a } 6 \text { anos }\end{array}$ & $\begin{array}{l}\text { Identificar fatores de risco } \\
\text { para obesidade em } \\
\text { pré-escolares }\end{array}$ \\
\hline Hui et al. 10 & 2003 & Hong Kong & Caso-controle & 343 & 1 unidade de saúde & 6 a 7 anos & $\begin{array}{l}\text { Identificar fatores de risco } \\
\text { para sobrepeso }\end{array}$ \\
\hline $\begin{array}{l}\text { Takahashi } \\
\text { et al. } 11\end{array}$ & 1999 & Japão & $\begin{array}{l}\text { Caso-controle } \\
\text { pareado por } \\
\text { sexo e mês de } \\
\text { nascimento }\end{array}$ & $\begin{array}{l}1.281 \text { crianças } \\
\text { (427 casos e } 854 \\
\text { controles) selecio- } \\
\text { nadas do Toyama } \\
\text { Study }\end{array}$ & $\begin{array}{l}\text { Crianças acompa- } \\
\text { nhadas pelo serviço } \\
\text { de saúde em uma } \\
\text { localidade do Japão }\end{array}$ & 3 anos & $\begin{array}{l}\text { Avaliar a associação entre } \\
\text { hábitos de vida e obesidade } \\
\text { na infância }\end{array}$ \\
\hline Tene et al. 12 & 2003 & México & Caso-controle & $\begin{array}{l}322 \text { ( } 20 \text { casos e } \\
44 \text { controles) }\end{array}$ & $\begin{array}{l}\text { Escolares de } 1 \underline{a} \text { e } \\
\text { 2a série do ensino } \\
\text { fundamental em zona } \\
\text { urbana e rural }\end{array}$ & 7 a 8 anos & $\begin{array}{l}\text { Avaliar a associação entre } \\
\text { o peso elevado ao nascer } \\
\text { e a obesidade infantil }\end{array}$ \\
\hline
\end{tabular}


Principais resultados em ordem cronológica dos estudos com associação entre peso ao nascer e obesidade na infância, $1993-2003$.

\begin{tabular}{|c|c|c|c|c|c|c|c|}
\hline Referência & Data & $\begin{array}{l}\text { Características } \\
\text { da exposição: } \\
\text { peso ao nascer }\end{array}$ & $\begin{array}{l}\text { Definição de } \\
\text { sobrepeso/ } \\
\text { Obesidade }\end{array}$ & Co-variáveis & $\begin{array}{l}\text { Variável de } \\
\text { resultado }\end{array}$ & $\begin{array}{l}\text { Tipo de } \\
\text { associação/ } \\
\text { Resultados } \\
\text { principais }\end{array}$ & $\begin{array}{l}\text { Escores/ } \\
\text { Comentários }\end{array}$ \\
\hline Baker et al. 30 & 2004 & $\begin{array}{l}\text { Peso ao } \\
\text { nascer }(g) .\end{array}$ & $\begin{array}{l}\text { Risco de sobre- } \\
\text { peso: ganho de } \\
\text { peso adicional a } \\
500 \mathrm{~g} \text { (o equiva- } \\
\text { lente à diferença } \\
\text { entre o percentil } \\
75 \text { e o percentil } \\
85 \text { para esta } \\
\text { população). }\end{array}$ & $\begin{array}{l}\text { Maternas: IMC, } \\
\text { primiparidade, } \\
\text { IMC pré-gesta- } \\
\text { cional, fumar } \\
\text { durante a gesta- } \\
\text { ção, ganho de } \\
\text { peso gestacional, } \\
\text { duração da } \\
\text { gestação. } \\
\text { Da criança: sexo, } \\
\text { peso ao nascer, } \\
\text { comprimento à } \\
\text { idade de } 1 \text { ano, } \\
\text { idade em semanas } \\
\text { quando da primei- } \\
\text { ra medição antro- } \\
\text { pométrica (1 ano), } \\
\text { duração do alei- } \\
\text { tamento, época } \\
\text { de introdução de } \\
\text { alimentos com- } \\
\text { plementares. }\end{array}$ & $\begin{array}{l}\text { Ganho de } \\
\text { peso (g). } \\
\text { Diferença do peso } \\
\text { à idade de } 1 \text { ano } \\
\text { e o peso ao } \\
\text { nascer (variável } \\
\text { contínua). }\end{array}$ & $\begin{array}{l}\text { Associação } \\
\text { negativa. } \\
\text { Houve uma } \\
\text { redução de }-0,4 \mathrm{~g} \\
\text { no ganho de peso } \\
\text { para cada grama } \\
\text { a mais no peso } \\
\text { ao nascer } \\
\text { (p <0,0001). } \\
\text { A obesidade ma- } \\
\text { terna (IMC } \geq 30 \text { ), } \\
\text { o curto período } \\
\text { de aleitamento } \\
\text { materno e a intro- } \\
\text { dução precoce } \\
\text { de alimentos } \\
\text { complementares } \\
\text { estiveram asso- } \\
\text { ciados com um } \\
\text { ganho de peso } \\
\text { adicional de } 700 \mathrm{~g} \text {. } \\
\text { Houve efeito de } \\
\text { interação para } \\
\text { períodos de alei- } \\
\text { tamento < } 20 \\
\text { semanas e época } \\
\text { de introdução de } \\
\text { alimentos no } \\
\text { ganho de peso. }\end{array}$ & $\begin{array}{l}\text { Escore: } 21 \\
\text { A amostra compreendeu } \\
70,7 \% \text { da população } \\
\text { elegível. A proporção de } \\
\text { mães fumantes foi maior } \\
\text { no grupo excluído } \\
\text { ( } p<0,005) \text {, o qual } \\
\text { implicaria em um maior } \\
\text { número de crianças com } \\
\text { baixo peso ao nascer, } \\
\text { com menor período de } \\
\text { aleitamento materno e } \\
\text { com um ganho de peso } \\
\text { adicional à idade de } \\
1 \text { ano. }\end{array}$ \\
\hline $\begin{array}{l}\text { Danielzik } \\
\text { et al. } 24\end{array}$ & 2004 & $\begin{array}{l}\text { Peso ao nascer } \\
\text { (g) para idade } \\
\text { gestacional cate- } \\
\text { gorizado em } \\
\text { percentis como: } \\
\text { baixo < 10/médio: } \\
\text { 10-90/alto: > } 90 \\
\text { Específico para } \\
\text { sexo segundo a } \\
\text { referência popu- } \\
\text { lacional da } \\
\text { Alemanha. }\end{array}$ & $\begin{array}{l}\text { Sobrepeso: IMC } \\
\geq \text { percentil } 90 \text { e } \\
97 \text {; Obeso: > } 97 \\
\text { Massa gorda: } \\
\text { soma das dobras } \\
\text { cutâneas tríceps, } \\
\text { bíceps, subesca- } \\
\text { pular e suprailíaca } \\
\text { e por bioimpe- } \\
\text { dância elétrica. }\end{array}$ & $\begin{array}{l}\text { Obesidade dos } \\
\text { pais e irmãos, } \\
\text { grau de escolari- } \\
\text { dade (variável } \\
\text { sócio-econômica), } \\
\text { ausência de } \\
\text { companheiro, } \\
\text { hábito de fumar, } \\
\text { práticas alimen- } \\
\text { tares, atividade } \\
\text { física, peso ao } \\
\text { nascer, aleita- } \\
\text { mento materno } \\
\text { e estado nutricio- } \\
\text { nal dos irmãos. }\end{array}$ & $\begin{array}{l}\text { Sobrepeso e } \\
\text { obesidade } \\
\text { infantil (variável } \\
\text { dicotômica). }\end{array}$ & $\begin{array}{l}\text { O peso ao nascer } \\
\text { esteve associado } \\
\text { com obesidade, } \\
\text { mas não com } \\
\text { sobrepeso. Essa } \\
\text { associação foi } \\
\text { positiva para } \\
\text { meninas: meninas } \\
\text { que nasceram } \\
\text { com peso elevado } \\
\text { tiveram } 3,2 \text { vezes } \\
\text { mais chances de } \\
\text { apresentar obesi- } \\
\text { dade (IC95\%: } \\
\text { 1,3-7,8); e, nega- } \\
\text { tiva para os meni- } \\
\text { nos: meninos nas- } \\
\text { cidos com baixo } \\
\text { peso tiveram } \\
\text { 13,7 vezes mais } \\
\text { chances de serem } \\
\text { obesos (IC95\%: } \\
1,8-105,7) \text { contro- } \\
\text { lando para os } \\
\text { demais fatores } \\
\text { de risco. }\end{array}$ & $\begin{array}{l}\text { Escore: } 18 \\
\text { Foi utilizado o modelo de } \\
\text { regressão logística. } \\
53 \% \text { da população } \\
\text { elegível tinha dados } \\
\text { completos. } \\
\text { O estudo não informa } \\
\text { sobre as características } \\
\text { dos não participantes. }\end{array}$ \\
\hline
\end{tabular}


Tabela 2 (continuação)

\begin{tabular}{|c|c|c|c|c|c|c|c|}
\hline Referência & Data & $\begin{array}{l}\text { Características } \\
\text { da exposição: } \\
\text { peso ao nascer }\end{array}$ & $\begin{array}{l}\text { Definição de } \\
\text { sobrepeso/ } \\
\text { Obesidade }\end{array}$ & Co-variáveis & $\begin{array}{l}\text { Variável de } \\
\text { resultado }\end{array}$ & $\begin{array}{l}\text { Tipo de } \\
\text { associação/ } \\
\text { Resultados } \\
\text { principais }\end{array}$ & $\begin{array}{l}\text { Escores/ } \\
\text { Comentários }\end{array}$ \\
\hline $\begin{array}{l}\text { Drachler } \\
\text { et al. } 8\end{array}$ & 2003 & $\begin{array}{l}\text { Peso ao nascer } \\
\text { para idade ges- } \\
\text { tacional: peque- } \\
\text { nas < percentil } \\
10 ; \text { adequadas; } \\
\text { grandes > per- } \\
\text { centil } 90 .\end{array}$ & $\begin{array}{l}\text { Sobrepeso = } \\
\text { peso-para altura/ } \\
\text { comprimento: } \\
2 \text { escores Z > } \\
\text { mediana NCHS } \\
\text { (1977) segundo } \\
\text { o sexo e a idade } \\
\text { (variável dicotô- } \\
\text { mica). }\end{array}$ & $\begin{array}{l}\text { Sócio-econômicas; } \\
\text { demográficas; } \\
\text { ambiente social } \\
\text { imediato; eventos } \\
\text { de saúde (cresci- } \\
\text { mento intra- } \\
\text { uterino). }\end{array}$ & $\begin{array}{l}\text { Sobrepeso na } \\
\text { infância (variável } \\
\text { dicotômica). }\end{array}$ & $\begin{array}{l}\text { Associação positi- } \\
\text { va para sobrepe- } \\
\text { so: a chance foi } \\
\text { maior entre os } \\
\text { nascidos grandes } \\
\text { para a idade } \\
\text { gestacional e } \\
\text { menor entre os } \\
\text { nascidos peque- } \\
\text { nos para a idade } \\
\text { gestacional. } \\
\text { (OR: } 2,29 \text { e } 0,57 \\
\text { P }<0,001) \text {. }\end{array}$ & $\begin{array}{l}\text { Escore: } 20 \\
\text { Não foram considerados } \\
\text { as variáveis peso e altura } \\
\text { dos pais, bem como } \\
\text { outros fatores associados } \\
\text { à obesidade infantil } \\
\text { (hábitos alimentares, } \\
\text { aleitamento materno, } \\
\text { atividade física). }\end{array}$ \\
\hline $\begin{array}{l}\text { Eriksson } \\
\text { et al. } 17\end{array}$ & 2001 & $\begin{array}{l}\text { Peso ao } \\
\text { nascer }(\mathrm{g}) \\
\text { Comprimento } \\
\text { ao nascer }(\mathrm{cm}) \\
\text { Índice ponderal: } \\
\text { peso nascer/ } \\
\text { comprimento } 3 \\
\left(\mathrm{Kg} / \mathrm{m}^{3}\right)\end{array}$ & $\begin{array}{l}\text { Obesidade: } \\
\mathrm{IMC}>30 \mathrm{Kg} / \mathrm{m}^{2}\end{array}$ & $\begin{array}{l}\text { Idade gestacional; } \\
\text { altura e idade } \\
\text { materna; ocupa- } \\
\text { ção dos pais; } \\
\text { índice de aglo- } \\
\text { meração (número } \\
\text { de pessoas na } \\
\text { família/número } \\
\text { de cômodos). }\end{array}$ & $\begin{array}{l}\text { Incidência de } \\
\text { obesidade na vida } \\
\text { adulta; mudança } \\
\text { de escores Z no } \\
\text { peso para idade } \\
\text { e altura para } \\
\text { idade e no IMC, } \\
\text { do nascimento } \\
\text { aos } 7 \text { e aos } 15 \\
\text { anos (variável } \\
\text { dicotômica). }\end{array}$ & $\begin{array}{l}\text { Associação posi- } \\
\text { tiva: houve } \\
\text { uma correlação } \\
\text { positiva entre } \\
\text { peso ao nascer e } \\
\text { obesidade para } \\
\text { meninos. } \\
\text { A cada aumento } \\
\text { de peso ao nascer } \\
\text { e de IMC aos } 7 \\
\text { anos, as chances } \\
\text { de obesidade fu- } \\
\text { tura aumentaram. }\end{array}$ & $\begin{array}{l}\text { Escore: } 17 \\
\text { O estudo avaliou o efeito } \\
\text { combinado do peso ao } \\
\text { nascer e do IMC à idade } \\
\text { de } 7 \text { anos no risco de } \\
\text { obesidade em adultos. } \\
\text { O estudo refere uma } \\
\text { associação positiva entre } \\
\text { o peso ao nascer e o IMC } \\
\text { aos } 7 \text { anos, sem mostrar } \\
\text { o valor da medida de } \\
\text { efeito para essa faixa } \\
\text { etária. }\end{array}$ \\
\hline Frye et al. 13 & 2003 & $\begin{array}{l}\text { Peso ao nascer } \\
\text { (g) categorizado } \\
\text { como: baixo } \\
\text { peso ao nascer } \\
<2.500 \mathrm{~g} \text { (sim } \\
\text { ou não). }\end{array}$ & $\begin{array}{l}\text { Sobrepeso: } \\
\text { IMC } \geq 25 \\
\text { Obesidade: } \\
\text { IMC } \geq 30 \\
\text { Específico para } \\
\text { sexo e idade } \\
\text { (Cole et al. }{ }^{37)} \text {. }\end{array}$ & $\begin{array}{l}\text { Sexo, idade } \\
\text { agrupada, região, } \\
\text { estação climática, } \\
\text { grau de escolari- } \\
\text { dade, amamenta- } \\
\text { ção, período de } \\
\text { acompanhamento. }\end{array}$ & $\begin{array}{l}\text { Sobrepeso em } \\
\text { escolares nas } \\
\text { idades: } 5-7,8-10 \\
\text { e } 11-14 \text { anos } \\
\text { (variável } \\
\text { dicotômica). }\end{array}$ & $\begin{array}{l}\text { Associação posi- } \\
\text { tiva para sobre- } \\
\text { peso: quanto } \\
\text { maior o peso ao } \\
\text { nascer, maior foi } \\
\text { a chance de } \\
\text { sobrepeso. } \\
\text { Nascidos com } \\
\text { peso } \geq 4 \text { Kg tive- } \\
\text { ram } 2,7 \text { vezes } \\
\text { mais chances de } \\
\text { apresentar sobre- } \\
\text { peso; o baixo } \\
\text { peso ao nascer } \\
\text { e o elevado grau } \\
\text { de escolaridade } \\
\text { materna foram } \\
\text { protetores para } \\
\text { sobrepeso e } \\
\text { obesidade. }\end{array}$ & $\begin{array}{l}\text { Escore: } 18 \\
\text { O peso ao nascer foi } \\
\text { obtido de registros. Para } \\
\text { aferição do peso entre } \\
\text { os inquéritos, foram } \\
\text { utilizadas duas diferentes } \\
\text { balanças (apenas } \\
\text { calibradas). A análise } \\
\text { final foi ajustada para } \\
\text { sexo, porém não houve } \\
\text { ajuste para obesidade } \\
\text { dos pais. }\end{array}$ \\
\hline He et al. 9 & 2000 & $\begin{array}{l}\text { Peso ao nascer } \\
\text { (g) categorizado } \\
\text { como: } \geq 4.000 \\
\text { ou }<4.000\end{array}$ & $\begin{array}{l}\text { Obesidade: peso } \\
\text { para-altura > } \\
120 \% \text { da refe- } \\
\text { rência NCHS } \\
\text { segundo o sexo } \\
\text { e a idade. }\end{array}$ & $\begin{array}{l}\text { Tipo de atividade } \\
\text { e características } \\
\text { psicológicas na } \\
\text { infância, padrão } \\
\text { alimentar, aleita- } \\
\text { mento materno, } \\
\text { educação dos } \\
\text { pais obesidade } \\
\text { dos pais (IMC pai } \\
\text { e da mãe > 25). }\end{array}$ & $\begin{array}{l}\text { Obesidade na } \\
\text { infância (variável } \\
\text { dicotômica). }\end{array}$ & $\begin{array}{l}\text { Associação posi- } \\
\text { tiva para obesi- } \\
\text { dade: o peso ao } \\
\text { nascer } \geq 4 \mathrm{Kg} \text { foi } \\
\text { o principal fator } \\
\text { de risco entre } \\
\text { crianças < de } 3 \\
\text { anos (OR: } 4,02 \text { ). } \\
\text { Em crianças de } \\
3 \text { a } 6 \text { anos, o } \\
\text { principal fator de } \\
\text { risco foi a obesi- } \\
\text { dade dos pais (OR: } \\
4,92), \text { seguido do } \\
\text { peso ao nascer } \\
\text { (OR: } 3,02) ;(p: 0,005 \\
\text { e p: } 0,001) \text {. }\end{array}$ & $\begin{array}{l}\text { Escore: } 21 \\
\text { O peso ao nascer foi } \\
\text { obtido dos registros } \\
\text { hospitalares. As análises } \\
\text { foram ajustadas para os } \\
\text { principais fatores de risco. } \\
\end{array}$ \\
\hline
\end{tabular}

(continua) 


\begin{tabular}{|c|c|c|c|c|c|c|c|}
\hline Referência & Data & $\begin{array}{l}\text { Características } \\
\text { da exposição: } \\
\text { peso ao nascer }\end{array}$ & $\begin{array}{l}\text { Definição de } \\
\text { sobrepeso/ } \\
\text { Obesidade }\end{array}$ & Co-variáveis & $\begin{array}{l}\text { Variável de } \\
\text { resultado }\end{array}$ & $\begin{array}{l}\text { Tipo de } \\
\text { associação/ } \\
\text { Resultados } \\
\text { principais }\end{array}$ & $\begin{array}{l}\text { Escores/ } \\
\text { Comentários }\end{array}$ \\
\hline Hui et al. 10 & 2003 & $\begin{array}{l}\text { Peso ao } \\
\text { nascer }(\mathrm{g})\end{array}$ & $\begin{array}{l}\text { Sobrepeso: } \\
\text { IMC } \geq \text { percentil } \\
92 \text { da referência } \\
\text { populacional } \\
\text { asiática. }\end{array}$ & $\begin{array}{l}\text { Obesidade dos } \\
\text { pais, pai fumante, } \\
\text { ingestão energé- } \\
\text { tica } \geq 1.600 \mathrm{Kcal} \\
\text { diárias, poucas } \\
\text { horas de sono. }\end{array}$ & $\begin{array}{l}\text { Sobrepeso na } \\
\text { infância (variável } \\
\text { dicotômica). }\end{array}$ & $\begin{array}{l}\text { Associação posi- } \\
\text { tiva para sobre- } \\
\text { peso: a chance } \\
\text { de sobrepeso } \\
\text { aumentou com } \\
\text { o aumento do } \\
\text { peso ao nascer } \\
\text { (OR: } 2,13 \text { e } 4,89 \\
\text { entre } 3 \text { a } 3,5 \text { e } \\
\geq 3,5 \mathrm{Kg} ; \mathrm{p}<0,001 \text { ). }\end{array}$ & $\begin{array}{l}\text { Escore: } 18 \\
\text { O estudo se restringe } \\
\text { a } 386 \text { estudantes que } \\
\text { freqüentavam um dos } \\
\text { serviços de atendimento } \\
\text { à saúde. O peso ao } \\
\text { nascer e o peso dos pais } \\
\text { foram referidos. }\end{array}$ \\
\hline $\begin{array}{l}\text { Monteiro } \\
\text { et al. } 16\end{array}$ & 2003 & $\begin{array}{l}\text { Peso ao nascer } \\
\text { (g) categorizado } \\
\text { como: }<2.500 \\
2.500-3.999 \\
\geq 4.000 \text { e segundo } \\
\text { a idade gestacio- } \\
\text { nal como: RCIU: } \\
<\text { p10*. }\end{array}$ & $\begin{array}{l}\text { Sobrepeso: } \\
\text { IMC } \geq \text { percentil } \\
85 \text { específico } \\
\text { para sexo e } \\
\text { idade (NHANES } \\
\text { I, 1997**) } \\
\text { Obesidade: } \\
\text { sobrepeso + } \\
\text { dobras cutâneas } \\
\text { tricipital e } \\
\text { subescapular } \\
\geq \text { percentil } 90 .\end{array}$ & $\begin{array}{l}\text { Sócio-econômicas, } \\
\text { perinatais, antro- } \\
\text { pométricas e o } \\
\text { crescimento } \\
\text { rápido entre } \\
\text { 1882-1984 e } \\
1984-1996 .\end{array}$ & $\begin{array}{l}\text { Obesidade e } \\
\text { sobrepeso na } \\
\text { adolescência } \\
\text { (variável } \\
\text { dicotômica). }\end{array}$ & $\begin{array}{l}\text { O peso ao nascer } \\
\text { e o tamanho } \\
\text { alcançado aos } 20 \\
\text { e } 30 \text { meses foram } \\
\text { associados linear } \\
\text { e positivamente } \\
\text { com o sobrepeso } \\
\text { ( } p=0,047 \text { ), mas } \\
\text { não alcançaram } \\
\text { significância } \\
\text { estatística para } \\
\text { obesidade. } \\
\text { O RCIU não } \\
\text { esteve associado } \\
\text { nem com sobre- } \\
\text { peso nem com } \\
\text { obesidade. } \\
\text { O rápido ganho } \\
\text { de peso entre o } \\
\text { nascimento e } 20 \\
\text { meses e entre } 20 \\
\text { e } 43 \text { meses foi } \\
\text { associado com } \\
\text { o sobrepeso e } \\
\text { obesidade na } \\
\text { adolescência. }\end{array}$ & $\begin{array}{l}\text { Escore: } 21 \\
\text { As análises foram } \\
\text { ajustadas para as perdas } \\
\text { (28\%) e para diferentes } \\
\text { períodos de seguimento. } \\
\text { A informação do peso } \\
\text { pré-gestacional foi } \\
\text { obtida dos registros } \\
\text { hospitalares e, quando } \\
\text { não disponível, era } \\
\text { informada pela mãe. } \\
\text { A análise final foi } \\
\text { ajustada por renda } \\
\text { familiar, IMC materno } \\
\text { e ordem de nascimento } \\
\text { e o peso ao nascer, } \\
\text { porém o estudo não } \\
\text { descreve o valor desse } \\
\text { efeito. }\end{array}$ \\
\hline
\end{tabular}

(continua)

infantil, como a situação sócio-econômica 8, a obesidade materna 18 , os hábitos de vida 11 , o hábito de fumar materno 14,27, o aleitamento materno 15 e a relação de tendência de sobrepeso/obesidade 13. Além desses, quatro estudos se propuseram identificar outros importantes fatores de risco para sobrepeso/obesidade, tais como a obesidade dos pais, o elevado consumo energético, a situação sócio-econômica, sem especificar um único fator 9,10,24,26.

Quanto ao desenho dos estudos, sete estudos eram longitudinais $17,18,19,20,23,26,30$; seis, prospectivos $17,19,20,23,26,30$ - dos quais, quatro avaliaram crianças desde o nascimento até idades que variaram entre um ano e meio a sete anos 17,19,20,26, dois estudos incluíram adolescentes 17,23 , e um desses avaliou adultos 17 . Nove estudos eram transversais 8,13,14,15,16,22,24,25,27, um deles aninhado em um longitudinal 16 que avaliou as crianças ao nascer, aos vinte e aos quarenta e três meses; outro possuía representatividade nacional 25, e um outro realizou avaliações em escolares durante três períodos consecutivos 13 . Os outros quatro estudos restantes eram de caso-controle 9,10,11,12, um deles também com representatividade nacional incluiu crianças menores de um até seis anos 9 .

Quanto aos critérios de avaliação utilizados 28, observamos que nenhum estudo informou sobre as condições de "cegamento" (adaptadas para estudos observacionais) dos sujeitos ou dos examinadores em relação às exposições e desfechos. Além desse, os principais problemas metodológicos foram relacionados à confiabilidade na classificação das exposições, incluindo-se o peso ao nascer - principal exposição analisada. Outros problemas foram relacionados à falta de precisão das medidas antro- 
Tabela 2 (continuação)

\begin{tabular}{|c|c|c|c|c|c|c|c|}
\hline Referência & Data & $\begin{array}{l}\text { Características } \\
\text { da exposição: } \\
\text { peso ao nascer }\end{array}$ & $\begin{array}{l}\text { Definição de } \\
\text { sobrepeso/ } \\
\text { Obesidade }\end{array}$ & Co-variáveis & $\begin{array}{l}\text { Variável de } \\
\text { resultado }\end{array}$ & $\begin{array}{l}\text { Tipo de } \\
\text { associação/ } \\
\text { Resultados } \\
\text { principais }\end{array}$ & $\begin{array}{l}\text { Escores/ } \\
\text { Comentários }\end{array}$ \\
\hline $\begin{array}{l}\text { O'Callaghan } \\
\text { et al. } 26\end{array}$ & 1997 & $\begin{array}{l}\text { Percentis de peso } \\
\text { ao nascer (g): } \\
<\text { percentil 15, } \\
\text { 15-84, } 85-94 \text {, e } \\
\geq \text { percentil } 95 \\
\text { Peso para idade } \\
\text { gestacional: PIG } \\
<\text { percentil 10, } \\
\text { não PIG } \geq \\
\text { percentil } 10 \text {. }\end{array}$ & $\begin{array}{l}\text { Obesidade } \\
\text { moderada: per- } \\
\text { centil } \geq 85 \text { a } 94 \\
\text { Obesidade seve- } \\
\text { ra: percentil > 94. }\end{array}$ & $\begin{array}{l}\text { Da criança: sexo, } \\
\text { peso para idade } \\
\text { gestacional, índi- } \\
\text { ce ponderal, } \\
\text { situação de } \\
\text { saúde, hábitos } \\
\text { alimentares, } \\
\text { comportamento } \\
\text { hiperativo, } \\
\text { distúrbios do } \\
\text { sono, tipo de } \\
\text { alimentação e } \\
\text { duração do alei- } \\
\text { tamento materno } \\
\text { e problemas de } \\
\text { linguagem ou } \\
\text { comportamento. } \\
\text { Dos pais: IMC } \\
\text { pré-gestacional, } \\
\text { altura e idade } \\
\text { materna, grau de } \\
\text { educação, nível } \\
\text { de renda, situa- } \\
\text { ção conjugal e } \\
\text { sintomas de ansie- } \\
\text { dade e depressão } \\
\text { e IMC do pai. }\end{array}$ & $\begin{array}{l}\text { Obesidade } \\
\text { severa e } \\
\text { obesidade } \\
\text { moderada. }\end{array}$ & $\begin{array}{l}\text { Associação posi- } \\
\text { tiva com obesi- } \\
\text { dade moderada } \\
\text { e severa. } \\
\text { A chance de } \\
\text { obesidade severa } \\
\text { foi } 1,8 \text { vez maior } \\
\text { entre as crianças } \\
\text { que nasceram } \\
\text { com peso nos } \\
\text { percentis } 85 \text { a } 94 ; \\
\text { (IC95\%: } 1,1-2,9 \text { ) } \\
\text { comparadas } \\
\text { àquelas com } \\
\text { peso nos percen- } \\
\text { tis } 15 \text { a } 84 . \text { A } \\
\text { chance para } \\
\text { obesidade mode- } \\
\text { rada foi } 2 \text { vezes } \\
\text { maior para as } \\
\text { crianças que nas- } \\
\text { ceram com peso } \\
\geq \text { ao percentil } 95 \\
\text { (IC95\%: } 1,3-3,2 \text { ), } \\
\text { considerando } \\
\text { sexo, hábito } \\
\text { alimentar, tempo } \\
\text { de aleitamento } \\
\text { e horas de sono. } \\
\text { Crianças PIG } \\
\text { estiveram prote- } \\
\text { gidas contra } \\
\text { obesidade mode- } \\
\text { rada (OR: } 0,5 ; \\
\text { IC95\%: } 0,3-0,9) \text {. }\end{array}$ & $\begin{array}{l}\text { Escore: } 19 \\
\text { A amostra compreendeu } \\
72,19 \% \text { da população } \\
\text { elegível; os preditores } \\
\text { infantis para obesidade } \\
\text { aos } 5 \text { anos não estão } \\
\text { ajustados para as } \\
\text { características dos pais, } \\
\text { pois as análises foram } \\
\text { separadas utilizando-se } \\
\text { um modelo de regressão } \\
\text { logística para avaliar } \\
\text { preditores paternos e } \\
\text { outro para preditores da } \\
\text { criança. As medidas de } \\
\text { peso e altura dos pais } \\
\text { foram referidas, o que } \\
\text { poderia conduzir a um } \\
\text { erro aleatório tendendo } \\
\text { reduzir as estimativas } \\
\text { encontradas para o IMC. }\end{array}$ \\
\hline Ong et al. 19 & 2000 & $\begin{array}{l}\text { Escores Z de peso, } \\
\text { comprimento em } \\
\text { relação à média } \\
\text { da referência } \\
\text { populacional do } \\
\text { Reino Unido } \\
\text { (1990). Índice } \\
\text { ponderal (peso/ } \\
\text { comprimento2). }\end{array}$ & $\begin{array}{l}\text { Valores médios } \\
\text { mais elevados } \\
\text { de escores Z de } \\
\text { peso/idade, } \\
\text { altura/idade e } \\
\text { IMC maiores. } \\
\text { Valores percen- } \\
\text { tuais mais altos } \\
\text { de gordura } \\
\text { corporal (4 me- } \\
\text { didas de dobras } \\
\text { cutâneas), gordura } \\
\text { corporal total, } \\
\text { massa gorda e } \\
\text { circunferência da } \\
\text { cintura. }\end{array}$ & $\begin{array}{l}\text { Crescimento } \\
\text { acelerado até } 2 \\
\text { anos de idade e } \\
\text { dos } 2 \text { aos } 4 \text { anos } \\
\text { (catch-up) = } \\
\text { ganho de peso e } \\
\text { comprimento } \\
\text { acima de } 0,67 \\
\text { escore } Z \text { entre o } \\
\text { nascimento e os } \\
2 \text { anos. } \\
\text { As variáveis: } \\
\text { altura dos pais, } \\
\text { peso materno ao } \\
\text { nascer, primipari- } \\
\text { dade e tempo de } \\
\text { aleitamento foram } \\
\text { parte da análise } \\
\text { bivaridada. }\end{array}$ & $\begin{array}{l}\text { Obesidade aos } \\
5 \text { anos (variáveis } \\
\text { contínuas). }\end{array}$ & $\begin{array}{l}\text { Associação inver- } \\
\text { sa entre o peso } \\
\text { ao nascer e a } \\
\text { obesidade: } \\
\text { crianças que } \\
\text { nasceram com } \\
\text { menor peso, } \\
\text { comprimento e } \\
\text { índice ponderal } \\
\text { cresceram mais } \\
\text { rápido entre } 0 \text { e } \\
2 \text { anos. Aos } 5 \\
\text { anos, eram mais } \\
\text { altas, mais pesa- } \\
\text { das e tinham } \\
\text { maior percentual } \\
\text { de gordura cor- } \\
\text { poral, massa } \\
\text { gorda total, IMC } \\
\text { e circunferência } \\
\text { da cintura. }\end{array}$ & $\begin{array}{l}\text { Escore: } 20 \\
\text { A amostra compreendeu } \\
63,5 \% \text { da amostra inicial } \\
\text { ( } n=1.335 \text { ), entretanto as } \\
\text { crianças não participantes } \\
\text { do estudo tinham peso } \\
\text { ao nascer similar; o } \\
\text { escore Z médio do peso } \\
\text { ao nascer foi de }-0,53, \text { e } \\
\text { o de comprimento, }-0,23, \\
\text { não configurando baixo } \\
\text { peso ou comprimento ao } \\
\text { nascer. As análises não } \\
\text { foram ajustadas para as } \\
\text { variáveis maternas e } \\
\text { perinatais. }\end{array}$ \\
\hline
\end{tabular}

(continua) 
Tabela 2 (continuação)

\begin{tabular}{|c|c|c|c|c|c|c|c|}
\hline Referência & Data & $\begin{array}{l}\text { Características } \\
\text { da exposição: } \\
\text { peso ao nascer }\end{array}$ & $\begin{array}{l}\text { Definição de } \\
\text { sobrepeso/ } \\
\text { Obesidade }\end{array}$ & Co-variáveis & $\begin{array}{l}\text { Variável de } \\
\text { resultado }\end{array}$ & $\begin{array}{l}\text { Tipo de } \\
\text { associação/ } \\
\text { Resultados } \\
\text { principais }\end{array}$ & $\begin{array}{l}\text { Escores/ } \\
\text { Comentários }\end{array}$ \\
\hline $\begin{array}{l}\text { Okosun } \\
\text { et al. } 22\end{array}$ & 2000 & $\begin{array}{l}\text { Peso ao } \\
\text { nascer (g). }\end{array}$ & $\begin{array}{l}\text { Peso }(\mathrm{Kg}), \\
\text { altura }(\mathrm{cm}) \\
\text { Adiposidade } \\
\text { subcutânea } \\
\text { central (STR) } \\
\text { subescapular/ } \\
\text { tricipital } \\
\text { Adiposidade } \\
\text { central - periférica } \\
\text { (CPR)\#: (subes- } \\
\text { capular + supra- } \\
\text { ilíaca)/(tríceps + } \\
\text { circunferência da } \\
\text { coxa) (medidas } \\
\text { contínuas). }\end{array}$ & $\begin{array}{l}\text { Sexo, idade } \\
\text { e IMC. }\end{array}$ & $\begin{array}{l}\text { Medidas subcu- } \\
\text { tâneas: pregas } \\
\text { tricipital, subes- } \\
\text { capular, supra- } \\
\text { ilíaca e da coxa } \\
\text { (variável } \\
\text { contínua). }\end{array}$ & $\begin{array}{l}\text { O peso ao nascer } \\
\text { foi associado } \\
\text { inversamente } \\
\text { com adiposidade } \\
\text { central e central- } \\
\text { periférica entre } \\
\text { crianças brancas, } \\
\text { negras e hispâni- } \\
\text { cas ( } p<0,05 \text { ). } \\
\text { A "programação } \\
\text { fetal" estaria } \\
\text { implicada na } \\
\text { associação entre } \\
\text { o peso ao nascer } \\
\text { e o acúmulo de } \\
\text { gordura subcutânea }\end{array}$ & $\begin{array}{l}\text { Escore: } 19 \\
\text { Avaliou a correlação e o } \\
\text { efeito do peso ao nascer } \\
\text { nas medidas de } \\
\text { adiposidade segundo } \\
\text { sexo, idade e IMC entre } \\
\text { brancos, negros e } \\
\text { hispano-americanos. } \\
\text { Não foram incluídos } \\
\text { outros fatores de risco, } \\
\text { como o IMC materno, } \\
\text { nível educacional e } \\
\text { aleitamento materno. }\end{array}$ \\
\hline $\begin{array}{l}\text { Overpeck } \\
\text { et al. } 25\end{array}$ & 2000 & $\begin{array}{l}\text { Peso ao nascer } \\
\text { (g): }<2.500, \\
2.500-3.999, \\
\geq 4.000 \\
\text { Peso ao nascer } \\
\text { (g) para a idade } \\
\text { gestacional } \\
\text { categorizado } \\
\text { como: PIG: < } \\
\text { percentil } 10, \text { AIG: } \\
\text { percentil } 10 \text { a } 89, \\
\text { GIG: } \geq \text { percentil } 90 \\
\text { segundo a refe- } \\
\text { rência específica. }\end{array}$ & $\begin{array}{l}\text { Peso, altura, } \\
\text { dobras cutâneas } \\
(\mathrm{mm}), \text { IMC } \\
\text { IMC > percentil } \\
85=\text { risco de } \\
\text { obesidade. }\end{array}$ & $\begin{array}{l}\text { As análises foram } \\
\text { categorizadas } \\
\text { para peso ao } \\
\text { nascer segundo a } \\
\text { idade gestacional } \\
\text { de acordo com } \\
\text { sexo e número } \\
\text { de partos entre } \\
\text { não hispânicos } \\
\text { brancos, negros } \\
\text { e méxico-ame- } \\
\text { ricanos. }\end{array}$ & $\begin{array}{l}\text { Peso, estatura, } \\
\text { IMC e medições } \\
\text { de pregas cutâ- } \\
\text { neas (variável } \\
\text { contínua). }\end{array}$ & $\begin{array}{l}\text { As crianças } \\
\text { méxico-norte- } \\
\text { americanas } \\
\text { tiveram as } \\
\text { maiores preva- } \\
\text { lências de IMC > } \\
\text { percentil } 85 \text { entre } \\
\text { os } 2 \text { e os } 6 \text { anos } \\
\text { de idade. No } \\
\text { entanto, as } \\
\text { médias de peso } \\
\text { ao nascer foram } \\
\text { significativamente } \\
\text { menores entre as } \\
\text { crianças negras } \\
\text { não hispânicas } \\
\text { nascidas com } \\
\text { peso AlG (cerca } \\
\text { de menos } 0,200 \mathrm{~g} \text { ) } \\
\text { comparadas às } \\
\text { demais. }\end{array}$ & $\begin{array}{l}\text { Escore: } 21 \\
\text { O estudo enfocou-se na } \\
\text { comparação de padrões } \\
\text { de crescimento entre } \\
\text { diferentes grupos raciais/ } \\
\text { étnicos norte-americanos; } \\
\text { apesar disso, foi possível } \\
\text { observar diferenças } \\
\text { significativas no peso ao } \\
\text { nascer entre os grupos } \\
\text { que poderiam ter } \\
\text { influenciado nesse padrão. } \\
\text { O estudo não mostra } \\
\text { associação entre o peso } \\
\text { ao nascer e o IMC. }\end{array}$ \\
\hline $\begin{array}{l}\text { Stettler } \\
\text { et al. } 20\end{array}$ & 2002 & $\begin{array}{l}\text { Peso ao } \\
\text { nascer (g). }\end{array}$ & $\begin{array}{l}\text { Sobrepeso: } \\
\text { IMC } \geq 95 \text { espe- } \\
\text { cífico para idade } \\
\text { e sexo\#\#. }\end{array}$ & $\begin{array}{l}\text { Taxa de ganho } \\
\text { de peso entre o } \\
\text { nascimento até } \\
\text { os } 4 \text { meses (prin- } \\
\text { cipal variável de } \\
\text { exposição), idade } \\
\text { gestacional, sexo, } \\
\text { raça, primeiro } \\
\text { filho, IMC, grau } \\
\text { de instrução } \\
\text { materna. }\end{array}$ & $\begin{array}{l}\text { Sobrepeso aos } \\
7 \text { anos (variável } \\
\text { dicotômica). }\end{array}$ & $\begin{array}{l}\text { Associação posi- } \\
\text { tiva para sobre- } \\
\text { peso: Para cada } \\
100 \text { g de aumen- } \\
\text { to no peso ao } \\
\text { nascer, aumentou } \\
\text { em } 6 \% \text { a chance } \\
\text { de sobrepeso } \\
\text { aos } 7 \text { anos (OR: } \\
1,06 \text {; IC95\%: } \\
1,04-1,08 \text { ) ajus- } \\
\text { tando para os de- } \\
\text { mais confusores. } \\
\text { (p < 0,001). Ao } \\
\text { incluir o peso aos } \\
12 \text { anos, a chance } \\
\text { diminuiu para } 2 \% \\
\text { sem apresentar } \\
\text { significância } \\
\text { estatística. }\end{array}$ & $\begin{array}{l}\text { Escore } 20 \\
\text { Houve ajuste para os } \\
\text { principais fatores de } \\
\text { risco. O peso pré- } \\
\text { gestacional foi referido; } \\
69,6 \% \text { dos indivíduos } \\
\text { inicialmente amostrados } \\
\text { se assemelharam aos não } \\
\text { participantes quanto ao } \\
\text { sexo e idade gestacional } \\
\text { e peso ao nascer. }\end{array}$ \\
\hline
\end{tabular}

(continua) 
Tabela 2 (continuação)

\begin{tabular}{|c|c|c|c|c|c|c|c|}
\hline Referência & Data & $\begin{array}{l}\text { Características } \\
\text { da exposição: } \\
\text { peso ao nascer }\end{array}$ & $\begin{array}{l}\text { Definição de } \\
\text { sobrepeso/ } \\
\text { Obesidade }\end{array}$ & Co-variáveis & $\begin{array}{l}\text { Variável de } \\
\text { resultado }\end{array}$ & $\begin{array}{l}\text { Tipo de } \\
\text { associação/ } \\
\text { Resultados } \\
\text { principais }\end{array}$ & $\begin{array}{l}\text { Escores/ } \\
\text { Comentários }\end{array}$ \\
\hline $\begin{array}{l}\text { Takahashi } \\
\text { et al. } 11\end{array}$ & 1999 & $\begin{array}{l}\text { Peso ao nascer } \\
\text { (g) categorizado } \\
\text { como: } \geq 3.500 \\
\text { ou }<3.500 \text {. }\end{array}$ & $\begin{array}{l}\text { Obesidade: } \\
\text { IMC } \geq 18\end{array}$ & $\begin{array}{l}\text { Sobrepeso dos } \\
\text { pais (IMC } \geq 24 \text { ), } \\
\text { atividade física, } \\
\text { tempo ocupado } \\
\text { em atividades de } \\
\text { lazer fora do lar, } \\
\text { regularidade das } \\
\text { refeições, consu- } \\
\text { mo de petiscos, } \\
\text { IMC ao nascer, } \\
\text { pessoa responsá- } \\
\text { vel pelos cuidados } \\
\text { da criança, horas } \\
\text { de sono (< ou } \\
\geq 10 \text { horas), } \\
\text { trabalho materno, } \\
\text { horas de sono, } \\
\text { consumo de pra- } \\
\text { tos salgados. }\end{array}$ & $\begin{array}{l}\text { Obesidade aos } \\
3 \text { anos (variável } \\
\text { dicotômica). }\end{array}$ & $\begin{array}{l}\text { Associação posi- } \\
\text { tiva para obesi- } \\
\text { dade. A chance } \\
\text { de obesidade } \\
\text { foi } 1,37 \text { vez maior } \\
\text { para crianças que } \\
\text { nasceram com } \\
\text { peso } \geq 3.500 \mathrm{~g} \\
\text { (IC95\%: } 1,05- \\
1,78) \text {. O IMC dos } \\
\text { pais } \geq 24 \text {, o curto } \\
\text { tempo de ativida- } \\
\text { des fora do lar } \\
\text { e o hábito de } \\
\text { "beliscar" irregu- } \\
\text { larmente foram } \\
\text { os demais fatores } \\
\text { associados à } \\
\text { obesidade. }\end{array}$ & $\begin{array}{l}\text { Escore: } 14 \\
82 \% \text { foram os partici- } \\
\text { pantes do estudo, porém } \\
\text { o estudo não descreve } \\
\text { as características das } \\
\text { crianças que não } \\
\text { foram incluídas. } \\
\text { As informações do peso } \\
\text { e comprimento ao nascer } \\
\text { foram referidas pelos } \\
\text { pais baseadas nos } \\
\text { registros de saúde da } \\
\text { criança. A informação do } \\
\text { peso e altura dos pais } \\
\text { foi referida. }\end{array}$ \\
\hline Tene et al. 12 & 2003 & $\begin{array}{l}\text { Peso elevado ao } \\
\text { nascer: }>3.900 \mathrm{~g}\end{array}$ & $\begin{array}{l}\text { Obesidade: peso } \\
\text { para altura > } 2 \\
\text { desvios padrão } \\
\text { da referência } \\
\text { local; peso para } \\
\text { altura > } 20 \% \\
\text { mediana segundo } \\
\text { o sexo e idade } \\
\text { (NCHS); peso } \\
\text { para altura > } \\
\text { percentil } 90 \\
\text { IMC. }\end{array}$ & Sexo, idade. & $\begin{array}{l}\text { Obesidade em } \\
\text { escolares de } \\
\text { 1a e 2a série pri- } \\
\text { mária (variável } \\
\text { dicotômica). }\end{array}$ & $\begin{array}{l}\text { Associação posi- } \\
\text { tiva para obesi- } \\
\text { dade: OR: } 2,55 \\
\text { (IC95\%: } 1,4-4,8) \\
\text { para crianças } \\
\text { que nasceram } \\
\text { com peso > } \\
3.900 \mathrm{~g} ; \text { OR: } 0,79 \\
\text { (IC95\%: } 0,7-0,9) \\
\text { para crianças com } \\
\text { pesos } \leq 3.900 \mathrm{~g} .\end{array}$ & $\begin{array}{l}\text { Escore: } 16 \\
\text { O estudo não descreve } \\
\text { a que porcentagem } \\
\text { da população alvo } \\
\text { corresponde à amostra } \\
\text { estudada. } \\
\text { Não incluiu outros fatores } \\
\text { de risco além do sexo e } \\
\text { idade. A possibilidade de } \\
\text { viés de classificação deve } \\
\text { ser considerada (viés de } \\
\text { memória). }\end{array}$ \\
\hline
\end{tabular}

(continua)

pométricas, padronização dos entrevistadores, ajustes para co-variáveis, descrição das características dos sujeitos perdidos e avaliação das perdas. Com relação à validade externa, em alguns estudos, os sujeitos não eram representativos da população da qual haviam sido selecionados.

O escore médio de qualidade metodológica foi igual a 18,4 (desvio padrão $=2,4$ ). Três estudos apresentaram escores inferiores a 16 11,14,23 (Tabela 2).

Embora o peso ao nascer estivesse presente como uma das variáveis independentes nos vinte artigos revisados, esse se constituiu como a principal variável de exposição em apenas três estudos 12,22,23, sendo 19 o maior valor de escore alcançado.

Em relação à definição da exposição, peso ao nascer foi variado e, na maioria das vezes, avaliado de forma categórica, empregando diferentes categorias de classificação, bem como diversas populações de referência. Dois estudos utilizaram o índice ponderal: peso ao nascer/comprimento $3\left(\mathrm{Kg} / \mathrm{m}^{3}\right)$ associado a outras medidas. E alguns estudos incluíram o comprimento ao nascer $(\mathrm{cm})$ independente do peso para avaliar o efeito de ambas as medidas na obesidade infantil.

O principal desfecho avaliado foi o sobrepeso e a obesidade, e alguns estudos analisaram também a obesidade central ou periférica $16,19,22,23,24,25$. Um estudo avaliou o "ganho de peso" desde o nascimento até os 18 meses como variável de desfecho 30 .

Quanto à associação entre o peso ao nascer e o sobrepeso e/ou obesidade na infância, as seguintes situações foram encontradas:

\section{- Associação com obesidade}

Oito estudos encontraram associação positiva com a obesidade. Os critérios utilizados para classificar obesidade foram variados, predominando o emprego do IMC (peso/altura 2 ). Os pontos de corte estabelecidos diferiram entre si: > percentil 9724,27 ; $\geq$ percentil 9518 ; > percentil 94 26; > percentil 90 12; IMC > 30Kg/m² 17; 
Tabela 2 (continuação)

\begin{tabular}{|c|c|c|c|c|c|c|c|}
\hline Referência & Data & $\begin{array}{l}\text { Características } \\
\text { da exposição: } \\
\text { peso ao nascer }\end{array}$ & $\begin{array}{l}\text { Definição de } \\
\text { sobrepeso/ } \\
\text { Obesidade }\end{array}$ & Co-variáveis & $\begin{array}{l}\text { Variável de } \\
\text { resultado }\end{array}$ & $\begin{array}{l}\text { Tipo de } \\
\text { associação/ } \\
\text { Resultados } \\
\text { principais }\end{array}$ & $\begin{array}{l}\text { Escores/ } \\
\text { Comentários }\end{array}$ \\
\hline $\begin{array}{l}\text { Toschke } \\
\text { et al. } 14\end{array}$ & 2002 & $\begin{array}{l}\text { Peso ao nascer } \\
\text { (g) categorizado } \\
\text { como baixo } \\
\text { peso ao nascer: } \\
<2.500 \text { (variável } \\
\text { dicotômica) (sim } \\
\text { ou não). }\end{array}$ & $\begin{array}{l}\text { Obesidade: } \\
\text { (IMC) > 97; } \\
\text { sobrepeso (IMC) } \\
\text { > 90. Específicos } \\
\text { para sexo e idade } \\
\text { de população de } \\
\text { crianças da } \\
\text { Alemanha (1997). }\end{array}$ & $\begin{array}{l}\text { Baixo peso ao } \\
\text { nascer, hábito de } \\
\text { fumar, aleitamen- } \\
\text { to materno, grau } \\
\text { de instrução dos } \\
\text { pais e prematuri- } \\
\text { dade. }\end{array}$ & $\begin{array}{l}\text { Obesidade na } \\
\text { infância (variável } \\
\text { dicotômica). }\end{array}$ & $\begin{array}{l}\text { O baixo peso ao } \\
\text { nascer explicou } \\
\text { parcialmente a } \\
\text { associação positi- } \\
\text { va entre o hábito } \\
\text { de fumar durante } \\
\text { a gestação e a } \\
\text { obesidade/sobre- } \\
\text { peso na infância. } \\
\text { A prevalência de } \\
\text { baixo peso foi } \\
\text { maior para bebês } \\
\text { cujas mães fuma- } \\
\text { ram durante a } \\
\text { gravidez (15,1\%) } \\
\text { comparadas } \\
\text { àquelas que } \\
\text { nunca fumaram } \\
\text { ou que fumaram } \\
\text { antes ou após a } \\
\text { gestação (p < } \\
0,01 \text { ). As chances } \\
\text { de obesidade e } \\
\text { sobrepeso foram } \\
\text { maiores para mães } \\
\text { que fumaram du- } \\
\text { rante a gestação } \\
\text { (OR: } 1,92 \text { (IC95\%: } \\
1,29-2,86 \text { ) e } 1,58 \\
\text { (IC95\%: } 1,23-2,04 \text { ) } \\
\text { comparadas às } \\
\text { não-fumantes, } \\
\text { ajustando para } \\
\text { baixo peso ao } \\
\text { nascer e demais } \\
\text { fatores de risco. }\end{array}$ & $\begin{array}{l}\text { Escore: } 15 \\
\text { O estudo avaliou a } \\
\text { associação entre o hábito } \\
\text { de fumar e a obesidade/ } \\
\text { sobrepeso controlando } \\
\text { pelo peso ao nascer e } \\
\text { demais co-variáveis. } \\
\text { O estudo parte de uma } \\
\text { hipótese a priori do } \\
\text { efeito protetor do baixo } \\
\text { peso ao nascer e a } \\
\text { obesidade/sobrepeso. } \\
\text { Entretanto, o efeito do } \\
\text { peso ao nascer não foi } \\
\text { discriminado na análise } \\
\text { final. } \\
\text { Não foram considerados } \\
\text { outros importantes } \\
\text { fatores de risco como a } \\
\text { obesidade dos pais, o } \\
\text { aleitamento materno, } \\
\text { hábitos alimentares e } \\
\text { atividade física. }\end{array}$ \\
\hline $\begin{array}{l}\text { von Kries } \\
\text { et al. } 15\end{array}$ & 1999 & $\begin{array}{l}\text { Peso ao nascer } \\
\text { (g) categorizado } \\
\text { como baixo peso } \\
\text { ao nascer: < } 2.500 \\
\text { (variável dicotô- } \\
\text { mica) (sim ou não). }\end{array}$ & $\begin{array}{l}\text { Obesidade: } \\
\text { (IMC) > 97; sobre- } \\
\text { peso (IMC) > } 90 \text {. } \\
\text { Específicos para } \\
\text { sexo e idade de } \\
\text { população de } \\
\text { crianças germâ- } \\
\text { nicas (1997). }\end{array}$ & $\begin{array}{l}\text { Aleitamento } \\
\text { materno, hábito } \\
\text { de fumar, grau } \\
\text { de instrução dos } \\
\text { pais e prematu- } \\
\text { ridade e quarto } \\
\text { próprio. }\end{array}$ & $\begin{array}{l}\text { Obesidade e } \\
\text { sobrepeso na } \\
\text { infância (variável } \\
\text { dicotômica). }\end{array}$ & $\begin{array}{l}\text { Associação posi- } \\
\text { tiva: crianças } \\
\text { nascidas de baixo } \\
\text { peso estão "pro- } \\
\text { tegidas" contra } \\
\text { o sobrepeso } \\
\text { (OR: } 0,68 ; \text { IC95\%: } \\
\text { 0,53-0,88) compa- } \\
\text { radas às demais. } \\
\text { As crianças que } \\
\text { receberam leite } \\
\text { materno por } 6 \\
\text { meses ou mais } \\
\text { tiveram uma } \\
\text { redução no risco } \\
\text { de sobrepeso e } \\
\text { obesidade de } \\
30 \% \text { a } 40 \%, \\
\text { respectivamente. }\end{array}$ & $\begin{array}{l}\text { Escore: } 20 \\
76,7 \% \text { dos indivíduos } \\
\text { constituíram a população } \\
\text { elegível do estudo; } \\
91,4 \% \text { tinham dados } \\
\text { completos e não houve } \\
\text { diferenças quanto às } \\
\text { médias e percentis do } \\
\text { IMC dos participantes do } \\
\text { estudo em relação aos } \\
\text { não participantes. } \\
\text { A análise incluiu os } \\
\text { principais fatores de risco. }\end{array}$ \\
\hline
\end{tabular}

(continua) 
Tabela 2 (continuação)

\begin{tabular}{|c|c|c|c|c|c|c|c|}
\hline Referência & Data & $\begin{array}{l}\text { Características } \\
\text { da exposição: } \\
\text { peso ao nascer }\end{array}$ & $\begin{array}{l}\text { Definição de } \\
\text { sobrepeso/ } \\
\text { Obesidade }\end{array}$ & Co-variáveis & $\begin{array}{l}\text { Variável de } \\
\text { resultado }\end{array}$ & $\begin{array}{l}\text { Tipo de } \\
\text { associação/ } \\
\text { Resultados } \\
\text { principais }\end{array}$ & $\begin{array}{l}\text { Escores/ } \\
\text { Comentários }\end{array}$ \\
\hline $\begin{array}{l}\text { von Kries } \\
\text { et al. } 27\end{array}$ & 2002 & $\begin{array}{l}\text { Peso ao nascer } \\
\text { (g) categorizado } \\
\text { como peso } \\
\text { elevado ao nas- } \\
\text { cer: > percentil } \\
90, \text { segundo refe- } \\
\text { rência nacional } \\
\text { para sexo e idade } \\
\text { gestacional (va- } \\
\text { riável dicotômi- } \\
\text { ca) (sim ou não). }\end{array}$ & $\begin{array}{l}\text { Obesidade: } \\
\text { IMC > percentil } \\
\text { 97; sobrepeso: } \\
\text { IMC > percentil } \\
90 . \text { Específicos } \\
\text { para sexo e idade } \\
\text { segundo o pro- } \\
\text { posto pelo } \\
\text { European Child- } \\
\text { hood Obesity } \\
\text { Group. }\end{array}$ & $\begin{array}{l}\text { Dos pais: escola- } \\
\text { ridade } \geq 10 \text { anos, } \\
\text { IMC } \geq 30 \text {, ausên- } \\
\text { cia de compa- } \\
\text { nheiro e hábito } \\
\text { de fumar durante } \\
\text { a gravidez (variá- } \\
\text { vel de exposição } \\
\text { principal). } \\
\text { Da criança: } \\
\text { introdução de } \\
\text { alimentos com- } \\
\text { plementares < } 4 \\
\text { meses peso ao } \\
\text { nascer }>\text { percentil } \\
90, \text { elevado ganho } \\
\text { de peso aos } 12 \\
\text { meses ( } \geq 2,34 \\
\text { vezes o peso ao } \\
\text { nascer), }>1 \text { hora } \\
\text { assistindo TV ou } \\
\text { videogame, ativi- } \\
\text { dades desportivas, } \\
\text { hábito alimentares } \\
\text { e aleitamento } \\
\text { materno. }\end{array}$ & $\begin{array}{l}\text { Obesidade e } \\
\text { sobrepeso na } \\
\text { infância (variável } \\
\text { dicotômica). }\end{array}$ & $\begin{array}{l}\text { Associação posi- } \\
\text { tiva para sobre- } \\
\text { peso e obesida- } \\
\text { de. As chances } \\
\text { de sobrepeso e } \\
\text { obesidade foram } \\
\text { maiores para } \\
\text { crianças nascidas } \\
\text { com peso > per- } \\
\text { centil } 90 \text { (OR: } \\
2,12 ; \text { IC95\%: } \\
1,52-3,46 \text { e OR: } \\
2,23 ; \text { IC95\%: } \\
1,27-3,90, \text { res- } \\
\text { pectivamente) } \\
\text { considerando os } \\
\text { demais fatores } \\
\text { de risco. }\end{array}$ & $\begin{array}{l}\text { Escore: } 21 \\
\text { O peso ao nascer foi } \\
\text { obtido do livro de } \\
\text { registro de nascimentos. } \\
\text { Os sujeitos excluídos da } \\
\text { amostra por informação } \\
\text { não confiável quanto à } \\
\text { principal variável de } \\
\text { exposição foram poste- } \\
\text { riormente comparados } \\
\text { com os sujeitos incluídos. } \\
\text { A variável "ganho de } \\
\text { peso elevado" foi } \\
\text { excluída da análise final } \\
\text { por estar fortemente } \\
\text { correlacionada com o } \\
\text { peso ao nascer, o qual } \\
\text { mostrou maior impacto } \\
\text { no efeito de fumar } \\
\text { durante a gestação e o } \\
\text { sobrepeso/obesidade na } \\
\text { infância. }\end{array}$ \\
\hline Walker et al. 23 & 2002 & $\begin{array}{l}\text { Peso ao nascer } \\
\text { (g) (variável } \\
\text { contínua). }\end{array}$ & $\begin{array}{l}\text { IMC > percentil } 85 \\
\text { (NCHS, 2000). }\end{array}$ & $\begin{array}{l}\text { Idade, gênero, } \\
\text { estágio da puber- } \\
\text { dade e tipos de } \\
\text { déficit nutricional } \\
\text { (chronically or } \\
\text { previously } \\
\text { stunted). }\end{array}$ & $\begin{array}{l}\text { Peso, altura, } \\
\text { percentual de } \\
\text { gordura corporal, } \\
\text { SSF, TSF e adi- } \\
\text { posidade sub- } \\
\text { cutânea central } \\
\text { (SSF/TSF) (variá- } \\
\text { vel contínua). }\end{array}$ & $\begin{array}{l}\text { O peso ao nascer } \\
\text { foi associado } \\
\text { positivamente } \\
\text { com o IMC aos } \\
7 \text { e } 11 \text { anos para } \\
\text { ambos os grupos } \\
\text { (com e sem } \\
\text { déficit de altura } \\
\text { para idade) } \\
\text { ( } p<0,001 \text { ). } \\
\text { Houve associação } \\
\text { negativa entre o } \\
\text { peso ao nascer } \\
\text { e a distribuição } \\
\text { de adiposidade } \\
\text { central aos } 11 \\
\text { anos de idade } \\
\text { ( } p<0,05 \text { ). }\end{array}$ & $\begin{array}{l}\text { Escore: } 14 \\
\text { A amostra deste estudo } \\
\text { originou-se de um ensaio } \\
\text { randomizado que avaliou } \\
\text { crianças residentes em } \\
\text { áreas de baixa renda. } \\
\text { Para este estudo, } 306 \\
\text { crianças foram compa- } \\
\text { radas: crianças com } \\
\text { déficit de altura para } \\
\text { idade (stunted) e sem } \\
\text { esse déficit. As crianças } \\
\text { com menor peso ao } \\
\text { nascer (stunted) tiveram } \\
\text { menores IMC, porém } \\
\text { maior distribuição de } \\
\text { adiposidade central. Não } \\
\text { houve associação entre } \\
\text { IMC e razão SST/TSF. } \\
\text { O peso ao nascer foi } \\
\text { obtido dos registros } \\
\text { hospitalares (73\%) e pela } \\
\text { informação da mãe. } \\
\text { A análise foi ajustada } \\
\text { apenas para sexo e idade. }\end{array}$ \\
\hline
\end{tabular}

(continua) 


\begin{tabular}{|c|c|c|c|c|c|c|c|}
\hline Referência & Data & $\begin{array}{l}\text { Características } \\
\text { da exposição: } \\
\text { peso ao nascer }\end{array}$ & $\begin{array}{l}\text { Definição de } \\
\text { sobrepeso/ } \\
\text { Obesidade }\end{array}$ & Co-variáveis & $\begin{array}{l}\text { Variável de } \\
\text { resultado }\end{array}$ & $\begin{array}{l}\text { Tipo de } \\
\text { associação/ } \\
\text { Resultados } \\
\text { principais }\end{array}$ & $\begin{array}{l}\text { Escores/ } \\
\text { Comentários }\end{array}$ \\
\hline Whitaker 18 & 2004 & $\begin{array}{l}\text { Peso ao nascer } \\
\text { para idade ges- } \\
\text { tacional catego- } \\
\text { rizado por per- } \\
\text { centis (PIG: < } \\
\text { percentil } 10 \text {, AIG: } \\
\text { percentis } 10 \text { a } 89 \text {, } \\
\text { GIG: } \geq \text { percentil 90) } \\
\text { segundo a refe- } \\
\text { rência específica } \\
\text { para população } \\
\text { hispânica e não } \\
\text { hispânica e como } \\
<2.500 \mathrm{~g} ; 2.500- \\
2.999 \mathrm{~g} ; \geq 3.000 \mathrm{~g} .\end{array}$ & $\begin{array}{l}\text { Obesidade: } \\
\text { IMC } \geq 95 \\
\text { percentil. } \\
\end{array}$ & $\begin{array}{l}\text { Obesidade } \\
\text { materna: IMC } \geq \\
30 \mathrm{Kg} / \mathrm{m}^{2} \text { no pri- } \\
\text { meiro trimestre } \\
\text { da gestação } \\
\text { (OMS). } \\
\text { Hábito de fumar, } \\
\text { primeiro filho. }\end{array}$ & $\begin{array}{l}\text { Obesidade aos } \\
2,3 \text { e } 4 \text { anos } \\
\text { (variável } \\
\text { dicotômica). }\end{array}$ & $\begin{array}{l}\text { Associação posi- } \\
\text { tiva: nascidos } \\
\text { GIG tiveram mais } \\
\text { chances de obe- } \\
\text { sidade aos } 2,3 \\
\text { e } 4 \text { anos (OR: } \\
2,33 ; 1,59 \text { e } 1,69) \text {. } \\
\text { O risco de obe- } \\
\text { sidade foi maior } \\
\text { entre crianças } \\
\text { cujas mães eram } \\
\text { obesas aos } 2,3 \\
\text { e } 4 \text { anos: } 2,0 \\
(1,7-2,3), 2,3 \\
(2,0-2,6) \text { e } 2,3 \\
(2,0-2,6), \text { respec- } \\
\text { tivamente. }\end{array}$ & $\begin{array}{l}\text { Escore: } 16 \\
\text { O estudo não descreve } \\
\text { informações dos } \\
\text { indivíduos que não foram } \\
\text { incluídos. Não fica clara a } \\
\text { probabilidade para os } \\
\text { principais desfechos } \\
\text { encontrados na análise } \\
\text { multivariada. As } \\
\text { informações obtidas na } \\
\text { rotina do programa e dos } \\
\text { registros podem estar } \\
\text { sujeitas a erros. }\end{array}$ \\
\hline
\end{tabular}

NCHS = National Center for Health Statistics; OMS = Organização Mundial da Saúde; IMC = Índice de Massa Corporal; $\mathrm{RCIU}=$ restrição do crescimento intra-uterino; OR = odds ratio; IC95\% = intervalo de confiança a $95 \%$; PIG = pequeno para idade gestacional; $\mathrm{AIG}=$ adequado para idade gestacional; GIG = grande para idade gestacional; SSF = prega cutânea subescapular; TSF = prega cutânea tricipital.

* Segundo o padrão de crescimento de crianças da Califórnia, Estados Unidos;

** First National Health and Nutrition Examination Survey (NHANES I), Estados Unidos, 1997;

*** Razão entre medida subescapular e tricipital. Indicador de distribuição relativa de adiposidade subcutânea central;

\# CPR: medidas subescapular + suprailíaca/medidas do tríceps + circunferência da coxa;

\#\# Centers for Disease Control and Prevention, Estados Unidos.

IMC $\geq 18 \mathrm{Kg} / \mathrm{m}^{2} 11$. Outros critérios empregados foram o peso para altura $>120 \%$ da mediana NCHS (National Center for Health Statistics) segundo o sexo e a idade 9,12 e o peso para altura $>2$ desvios padrão da referência local 12 .

Dos estudos acima citados, dois mostraram associação positiva também com o sobrepeso (IMC > percentil 90) ou obesidade moderada (IMC $\geq 85$ a 94 ) 26,27.

Um estudo encontrou associação direta entre o peso ao nascer e a obesidade apenas para meninas; para os meninos, essa associação foi inversa; não houve associação com sobrepeso (IMC $\geq$ percentil 90 a 97) 24 .

\section{- Associação com sobrepeso}

Sete estudos encontraram associação positiva com o sobrepeso. Os critérios utilizados para classificar sobrepeso também diferiram quanto aos índices, pontos de corte e referências populacionais. Seis artigos utilizaram o IMC para definir sobrepeso com os seguintes pontos de corte: IMC $\geq$ percentil 9520 ; $\geq$ percentil 9210 ; > percentil 9027 ; $\geq$ percentil 8516 ; > percentil $8523 ; \geq 25 \mathrm{Kg} / \mathrm{m}^{2}$ 13. Um estudo utilizou o peso para altura $>2$ escores $Z$ da mediana NCHS 8 . As referências populacionais empregadas foram diversas, tais como a referência asiática 10 , a referência para crianças germânicas 27 , as referências americanas 8,16,20.

Dois estudos acima também encontraram associação positiva com a obesidade 26,27.

\section{- Associação com obesidade central e periférica}

Dos seis artigos que avaliaram medidas de adiposidade central e/ou periférica e sua associação com demais fatores de risco, um estudo utilizou as medidas de adiposidade como complementares para avaliar obesidade e sua associação com fatores de risco 16.

Dois estudos encontraram associação inversa com o peso ao nascer: um deles utilizou a razão entre prega cutânea subescapular e tricipital entre crianças de 7 e 11 anos de idade 23; o outro avaliou o percentual de gordura corporal aos cinco anos de idade a partir de quatro medidas de dobras cutâneas 19 . Os demais estudos não mostram medidas de efeito específicas para esse desfecho.

Quanto aos dois estudos que enfocaram o baixo peso ao nascer $(<2.500 \mathrm{~g})$, entre as demais variáveis de exposição, apenas um descreveu o efeito dessa variável no excesso de peso. Ambos os estudos eram transversais e utilizaram a mesma fonte de dados: 
a) Em um artigo, o baixo peso ao nascer explicou, parcialmente, a associação positiva entre o hábito de fumar durante a gestação e a obesidade (IMC > 97) ou o sobrepeso (IMC > 90) aos 5 e 6 anos de idade sem mostrar o valor desse efeito 14 . b) O outro artigo mostrou o efeito parcial protetor do baixo peso ao nascer no sobrepeso de crianças dessa mesma faixa etária $(\mathrm{OR}=0,68$; IC95\%: 0,53-0,88) 15.

Dois estudos longitudinais prospectivos 19,30 focalizaram a mudança no percentil para ganho de peso, estatura ou ambos e incluíram o peso ao nascer como uma das variáveis ajustadas na análise final:

a) No estudo de Ong et al. 19, a associação inversa entre o peso ao nascer e a obesidade aos cinco anos foi mediada pelo crescimento acelerado (diferenças em escores $\mathrm{Z}$ de peso para comprimento $>0,67$ entre o nascimento e os dois anos de idade) 19,31.

b) Baker et al. 30 mostrou associação inversa entre o peso ao nascer e o ganho de peso avaliando a diferença entre o peso ao nascer e aos 12 meses acima de $500 \mathrm{~g}$ (o que correspondeu à mudança do percentil 75 para o 85 ).

\section{Discussão}

Os estudos revisados apresentaram heterogeneidade em muitas de suas características, como diferentes desenhos, diversas definições para sobrepeso e obesidade e diferentes formas de medir a exposição peso ao nascer. O peso ao nascer se constituiu como variável de interesse principal em apenas três dos estudos revisados. Além disso, os critérios empregados para definir sobrepeso e obesidade infantil diferiram entre si e quanto aos padrões de referência adotados. Quanto aos três artigos que enfocaram o peso ao nascer como principal variável de exposição, empregaram diferentes desenhos sendo um longitudinal 23 , outro transversal 22 e um desenho de caso-controle 12, o que limita a comparabilidade entre si. Ainda assim, dois desses estudos encontraram associação inversa com as medidas de adiposidade central aos 5 e 1122 e aos 7 e 11 anos de idade 23 . No estudo de Walker et al. 23, o peso ao nascer esteve associado positivamente com o IMC das crianças com e sem déficit de altura para idade. Quanto aos fatores de risco, poucos foram considerados na análise, como IMC e situação socioeconômica dos pais, o que restringe a interpretação dos resultados. Em relação aos demais artigos que avaliaram outros fatores de risco para o excesso de peso na infância, além do peso ao nascer, apresentaram uma ausência de ho- mogeneidade quanto aos fatores ajustados na análise, mesmo entre os estudos que avaliaram variáveis comuns de exposição como, por exemplo, o hábito de fumar durante a gestação 14,27.

Apesar das inúmeras limitações mencionadas, a sistematização dos artigos permitiu evidenciar uma associação predominantemente positiva entre o peso ao nascer e o desenvolvimento de algum tipo de obesidade na infância. Entretanto, constatamos que a contribuição do peso ao nascer tendeu a reduzir-se à medida que novas variáveis foram incorporadas no modelo. Quanto à associação com as medidas de adiposidade central, o número de artigos revisados não foi suficiente para confirmar as evidências de uma associação inversa com o peso ao nascer. Além disso, nem todos os artigos mostraram medidas de resultado para esse desfecho.

Os artigos que enfocaram o baixo peso ao nascer sugerem que crianças nascidas com baixo peso estariam mais "protegidas" contra a obesidade na infância 14,15. Além disso, observamos que alguns estudos que discutem o papel do peso ao nascer na obesidade durante a infância vêm apontando para novas direções, mostrando que, apesar de bastante explorado, esse tema não está esgotado.

Em relação à qualidade metodológica dos artigos, alguns estudos merecem comentários específicos.

O estudo de He et al. 9 foi desenvolvido em oito cidades das regiões Norte e Sul da China e incluiu crianças de um mês a sete anos de idade, acompanhadas anualmente pelo sistema de saúde local. Entretanto, por tratar-se de um estudo de caso-controle, a variável de desfecho foi categorizada como obeso ou não obeso, e a variável independente peso ao nascer foi também categorizada, encontrando-se risco de obesidade apenas para aquelas que nasceram com peso muito elevado $(\geq 4.000 \mathrm{~g})$.

O estudo de Monteiro et al. 16 foi um estudo transversal aninhado em uma coorte que avaliou a associação entre a velocidade do crescimento (considerado rápido para escores $\mathrm{Z}$ acima de 0,67 dos indicadores antropométricos segundo a referência NCHS) e o tamanho alcançado nos primeiros anos de vida, com o sobrepeso e a obesidade em adolescentes. O peso ao nascer foi associado linear e positivamente com o sobrepeso mesmo após ajustar por condições socioeconômicas e IMC pré-gestacional. Os resultados também mostraram uma associação positiva entre a "velocidade do crescimento durante a infância” e a prevalência de sobrepeso/obesidade na adolescência, mesmo ajustando para peso ao nascer. Com isso, fica 
evidente o papel de outras variáveis - avaliadas prospectivamente durante a infância - para explicar o aumento do sobrepeso que de outro modo poderia estar sendo atribuído ao peso ao nascer por si só. O estudo não descreve a associação entre o peso ao nascer e a velocidade do crescimento.

O estudo de Stettler et al. 20 avaliou de forma prospectiva a associação entre o "rápido ganho de peso" nos primeiros quatro meses de vida e o sobrepeso aos sete anos de idade em crianças norte-americanas nascidas a termo. A definição de crescimento rápido adotada foi uma variação igual ou maior $a+1$ escore $Z$ de peso para idade. $O$ peso ao nascer não mostrou diferenças significativas no ganho de peso nos primeiros quatro meses de vida. Contudo, os resultados mostraram uma associação entre o elevado peso ao nascer e o sobrepeso. E a análise final apontou uma associação independente entre a taxa de ganho de peso nos quatro primeiros meses de vida e o sobrepeso aos sete anos, ajustando por "peso ao nascer" e diversas variáveis. Ainda que o estudo priorizasse verificar a influência de fatores genéticos, não foi possível confirmar essa hipótese.

Em relação aos dois estudos metodologicamente mais consistentes que encontraram associação inversa com o peso ao nascer, ressaltamos o estudo de Baker et al. 30 , que incluiu, como variável de desfecho, o "ganho de peso" desde o nascimento até a idade de um ano. $\mathrm{O}$ peso ao nascer associou-se inversamente com o ganho de peso, mesmo com o ajuste por outros fatores de confusão, porém esse efeito reduziu-se quando a variável "comprimento da criança” foi excluída do modelo, indicando que parte significativa do ganho de peso deveu-se mais ao comprimento da criança do que ao peso ao nascer. As principais variáveis de interesse (duração do aleitamento materno e época de introdução dos alimentos) mostraram um efeito de interação com o ganho de peso ajustando pelos demais fatores de confusão. O estudo também não detectou causalidade reversa entre o peso ao nascer e a época de introdução de alimentos complementares. O estudo de Ong et al. 19 mostrou que as crianças que apresentaram maior velocidade no crescimento dos 0 aos 2 anos eram, em média, mais delgadas quando comparadas àquelas que não apresentaram crescimento rápido. A falta de ajuste para variáveis maternas e perinatais limitou a interpretação dos achados.

Quanto aos critérios utilizados, avaliar a qualidade dos artigos possibilitou uma identificação mais criteriosa das principais características metodológicas dos artigos selecionados e melhor sistematização dos resultados. Contudo, é particularmente limitado na pergunta "testes estatísticos utilizados para medir os principais desfechos foram apropriados?", restringindo muito esse aspecto da avaliação ao propor somente as seguintes opções: pequenas amostras deveriam utilizar testes não-paramétricos; e na falta de descrição da distribuição dos dados (normal ou não), dever-se-ia assumir que as estimativas utilizadas foram as mais adequadas. Evidentemente, frente ao desenvolvimento dos modelos lineares generalizados e suas extensões, essa classificação é insuficiente e pouco informativa. Além disso, a utilização de classificações de peso gerando variável binária como resposta é um limitante dos estudos analisados, pois respostas contínuas poderiam mostrar diferentes padrões de comportamento entre as associações. Essa estratégia também limita a detecção de associações não lineares, encontradas em alguns estudos na área de nutrição, principalmente entre adultos 3,32. Efeitos dessa natureza não poderiam ser identificados em um modelo de respostas binário. A maioria dos estudos revisados apresentou os resultados como variáveis binárias, utilizando o modelo de regressão logística, e apenas dois estudos justificaram o emprego de variáveis binárias. Apenas dois estudos mencionam a associação positiva e linear encontrada. Além disso, como a maior parte dos estudos não informa sobre o emprego de teste para avaliar o ajuste do modelo, não teríamos elementos suficientes para avaliar se o modelo estatístico utilizado foi realmente o mais adequado. Em face desse aspecto, sugerimos, a seguir, três questões referentes aos testes estatísticos empregados que poderiam complementar os critérios de avaliação propostos:

- O tipo de distribuição dos dados foi descrito pelo estudo?

- Existe alguma justificativa conceitual para o modelo estatístico aplicado?

- Foi realizado algum procedimento para avaliar o ajuste do modelo?

A possibilidade de um viés de publicação é outro aspecto que não pode ser desconsiderado, uma vez que achados significativos têm maior probabilidade de serem publicados em relação aos estudos que não apresentam significância estatística.

Outro ponto a ser discutido é o papel fundamental da abordagem dos estudos longitudinais com medidas repetidas que possibilitem identificar efeitos do peso ao nascer nos diferentes períodos de vida, reforçando ou reduzindo seu papel, conforme tem sido sugerido por Lucas et al. 33. Ainda que importantes va- 
riáveis tenham sido contempladas em alguns dos estudos, tais como IMC dos pais, raça/etnia, escolaridade materna, ordem do nascimento e situação sócio-econômica, poucos incorporaram métodos que permitem analisar o modelo de determinação da obesidade, modelando variáveis intervenientes, bem como estruturas de dependência próprias à análise de dados longitudinais 34,35 .

Um outro aspecto a ser ressaltado é a existência de duas correntes teóricas subjacentes aos estudos que avaliam o papel do peso ao nascer e seu efeito na obesidade futura. Uma delas enfatiza aspectos predominantemente biológicos, relacionados à hipótese da programação fetal, na qual o baixo peso ao nascer resultado de condições intra-uterinas adversas - promoveria uma reprogramação compensatória durante a infância, levando a um maior risco de doenças crônicas nos adultos 21 . A outra abordagem ressalta a influência de fatores pós-natais no risco de obesidade, tais como o ganho de peso durante a infância, independente dos aspectos relacionados à biologia fetal. Mais recentemente, um maior número de estudos inclui o efeito da "mudança nos escores de distribuição do peso para comprimento/altura" ou da "velocidade do crescimento" no desenvolvimento da obesidade infantil. Para esses, o rápido crescimento na infância pode constituir-se no principal fator de risco independente do peso ao nascer. $\mathrm{O}$ crescimento durante a infância também pode ser considerado um modificador do efeito do peso ao nascer. Como a exemplo do estudo de Eriksson et al. 17 em que o risco de obesidade em adultos foi maior quando, em crianças, tiveram um incremento no IMC ainda que nascidas com baixo peso.

Conforme a revisão de Parsons et al. 2 e de outros estudos 17,19, existem indícios de que o peso ao nascer tem seu efeito reduzido quando outros fatores são levados em conta na análise. Portanto, o cuidado metodológico para identificar os demais fatores que poderiam estar confundindo ou modificando o efeito do peso ao nascer na obesidade durante a infância é de fundamental importância para distinguir efeitos pré e pós-natais comumente atribuídos ao peso ao nascer. Por outro lado, a padronização das medidas e definiçõos de obesidade/sobrepeso infantis, já comentada em outros artigos, constitui medida fundamental para redução dos vieses.

Além disso, devido às contradições observadas entre os efeitos de determinados fatores associados ao peso ao nascer e à obesidade infantil como, por exemplo, escolaridade materna, uma hipótese que vem se fortalecendo é a contextual, tendo em vista que as distribuições do peso ao nascer e outras medidas corporais que avaliam o estado nutricional não seguem o mesmo padrão de comportamento entre os países 5,36. Com isso, o papel do peso ao nascer como um marcador das condições in utero no desenvolvimento da obesidade infantil poderia ser reforçado ou atenuado, dependendo das demais variáveis implicadas nessa associação que, por sua vez, podem refletir as características econômicas, sociais e culturais que distinguem cada região, atribuindo-se maior ou menor peso aos fatores ambientais (pós-natais). Se assim for, qualquer novo estudo manterá a contradição, pois dependerá do lugar e da população alvo. Desse modo, a abordagem utilizando métodos que incorporem efeito contextual - hierárquico, espacial - pode contribuir substancialmente para o esclarecimento dessas questões.

Por fim, neste trabalho cujo objetivo central foi avaliar o papel do peso ao nascer na determinação da obesidade infantil, verificamos a importância de aspectos pós-natais como a mudança nos escores Z para peso/altura, correlacionados ao sobrepeso e obesidade. Modificações do estado nutricional são decorrentes de alterações nos padrões de alimentação e de atividade dos indivíduos, que, por sua vez, resultam de um modelo de industrialização, urbanização e desenvolvimento econômico caracterizado por marcada globalização, que é um dos principais elementos desencadeadores das grandes mudanças no estilo de vida das populações em que o sobrepeso e obesidade são conseqüências marcantes em todo o mundo. Compreender essa dinâmica entre variáveis contextuais e variáveis individuais constitui tarefa essencial de forma a complementar o quadro de componentes associados ao aumento da obesidade infantil. 


\section{Resumo}

O peso ao nascer tem sido associado à obesidade/sobrepeso na infância. Contudo, os resultados são controversos. O objetivo desta revisão sistemática é identificar pontos concordantes e contraditórios sobre a associação entre o peso ao nascer e o excesso de peso em crianças de até sete anos de idade. Os primeiros oito artigos foram selecionados de uma revisão anterior que avaliou a associação entre fatores de risco e obesidade infantil. A busca na biblioteca PubMed, no período de 1993 a dezembro de 2004, com as palavraschaves "birth weight AND childhood", "obesity" $e$ "overweight", permitiu identificar outros artigos que enfocavam a associação entre o peso ao nascer e a obesidade infantil. Um total de 20 artigos preencheu os critérios para esta revisão. Apesar da heterogeneidade dos estudos, foi possível identificar associação predominantemente positiva entre o peso ao nascer e algum tipo de obesidade na infância. Por outro lado, a inconsistência de alguns aspectos relacionados ao peso ao nascer e à obesidade infantil sugere uma abordagem que incorpore o efeito do contexto no quadro de componentes associados à obesidade infantil.

Peso ao Nascer; Obesidade; Bem-Estar da Criança; Fatores de Risco; Revisão [Tipo de Publicação]

\section{Colaboradores}

E. B. Martins contribuiu com a busca dos artigos de interesse, redação e sistematização dos resultados. M. S. Carvalho sugeriu a metodologia do estudo e contribuiu com a revisão crítica do conteúdo inicial e após comentários do corpo editorial.

\section{Referências}

1. Doak CM, Adair LS, Monteiro C, Popkin BM. Overweight and underweight coexist within households in Brazil, China and Russia. J Nutr 2000; 130:2965-71.

2. Parsons TJ, Power C, Logan S, Summerbell CD. Childhood predictors of adult obesity: a systematic review. Int J Obes Relat Metab Disord 1999; 23 Suppl 8:S1-107.

3. Martorell R, Kettel-Khan L, Hughes ML, GrummerStrawn LM. Overweight and obesity in preschool children from developing countries. Int J Obes Relat Metab Disord 2000; 24:959-67.

4. Livingstone MB. Childhood obesity in Europe: a growing concern. Public Health Nutr 2001; 4:10916.

5. Martorell R, Stein AD, Schroeder DG. Early nutrition and later adiposity. J Nutr 2001; 131 Suppl: 874-80.

6. Rogers I. The influence of birthweight and intrauterine environment on adiposity and fat distribution in later life. Int J Obes Relat Metab Disord 2003; 27:755-77.

7. Lobstein T, Baur L, Uauy R. Obesity in children and young people: a crisis in public health. Obes Rev 2004; 5 Suppl 1:4-85.

8. Drachler ML, Macluf SPZ, Leite JCC, Aerts DRGC, Giugliani ERJ, Horta BL. Fatores de risco para sobrepeso em crianças no Sul do Brasil. Cad Saúde Pública 2003; 19:1073-81.

9. He Q, Ding ZY, Fong DY, Karlberg J. Risk factors of obesity in preschool children in China: a population-based case-control study. Int J Obes Relat Metab Disord 2000; 24:1528-36.

10. Hui LL, Nelson EA, Yu LM, Li AM, Fok TF. Risk factors for childhood overweight in 6- to 7-y-old Hong Kong children. Int J Obes Relat Metab Disord 2003; 27:1411-8.

11. Takahashi E, Yoshida K, Sugimori H, Miyakawa M, Izuno T, Yamagami T, et al. Influence factors on the development of obesity in 3-year-old children based on the Toyama study. Prev Med 1999; 28:293-6.

12. Tene CE, Espinoza-Mejía MY, Silva-Rosales NA, Girón-Carrillo JL. El peso elevado al nacer como factor de riesgo para obesidad infantil. Gac Med Mex 2003; 139:15-20.

13. Frye C, Heinrich J. Trends and predictors of overweight and obesity in East German children. Int J Obes Relat Metab Disord 2003; 27:963-9.

14. Toschke AM, Koletzko B, Slikker Jr. W, Hermann M, von Kries R. Childhood obesity is associated with maternal smoking in pregnancy. Eur J Pediatr 2002; 161:445-8.

15. von Kries R, Koletzko B, Sauerwald T, von Mutius E, Barnert D, Grunert V, et al. Breast feeding and obesity: cross sectional study. BMJ 1999; 319:14750.

16. Monteiro PO, Victora CG, Barros FC, Monteiro LM. Birth size, early childhood growth, and adolescent obesity in a Brazilian birth cohort. Int J Obes Relat Metab Disord 2003; 27:1274-82.

17. Eriksson J, Forsen T, Tuomilehto J, Osmond C, Barker D. Size at birth, childhood growth and obesity in adult life. Int J Obes Relat Metab Disord 2001; 25:735-40. 
18. Whitaker RC. Predicting preschooler obesity at birth: the role of maternal obesity in early pregnancy. Pediatrics 2004; 114:E29-36.

19. Ong KK, Ahmed ML, Emmett PM, Preece MA, Dunger DB. Association between postnatal catchup growth and obesity in childhood: prospective cohort study. BMJ 2000; 320:967-71.

20. Stettler N, Zemel BS, Kumanyika S, Stallings VA. Infant weight gain and childhood overweight status in a multicenter cohort study. Pediatrics 2002; 109:194-9.

21. Barker DJ. Fetal origins of coronary heart disease. BMJ 1995; 311:171-4.

22. Okosun IS, Liao Y, Rotimi CN, Dever GE, Cooper RS. Impact of birth weight on ethnic variations in subcutaneous and central adiposity in American children aged 5-11 years. A study from the Third National Health and Nutrition Examination Survey. Int J Obes Relat Metab Disord 2000; 24:479-84.

23. Walker SP, Gaskin PS, Powell CA, Bennett FI. The effects of birth weight and postnatal linear growth retardation on body mass index, fatness and fat distribution in mid and late childhood. Public Health Nutr 2002; 5:391-6.

24. Danielzik S, Czerwinski-Mast M, Langnase K, Dilba B, Muller MJ. Parental overweight, socioeconomic status and high birth weight are the major determinants of overweight and obesity in 5-7 yold children: baseline data of the Kiel Obesity Prevention Study (KOPS). Int J Obes Relat Metab Disord 2004; 28:1494-502.

25. Overpeck MD, Hediger ML, Ruan WJ, Davis WW, Maurer KR, Troendle JF, et al. Stature, weight, and body mass among young US children born at term with appropriate birth weights. J Pediatr 2000; 137:205-13.

26. O'Callaghan MJ, Williams GM, Andersen MJ, Bor W, Najman JM. Prediction of obesity in children at 5 years: a cohort study. J Paediatr Child Health 1997; 33:311-6.

27. von Kries R, Toschke AM, Koletzko B, Slikker Jr. W. Maternal smoking during pregnancy and childhood obesity. Am J Epidemiol 2002; 156:954-61.
28. Downs SH, Black N. The feasibility of creating a checklist for the assessment of the methodological quality both of randomised and non-randomised studies of health care interventions. J Epidemiol Community Health 1998; 52:377-84.

29. Silveira DS, Santos IS. Adequação do pré-natal e peso ao nascer: uma revisão sistemática. Cad Saúde Pública 2004; 20:1160-8.

30. Baker JL, Michaelsen KF, Rasmussen KM, Sorensen TI. Maternal prepregnant body mass index, duration of breastfeeding, and timing of complementary food introduction are associated with infant weight gain. Am J Clin Nutr 2004; 80:1579-88.

31. Ong KK, Dunger DB. Birth weight, infant growth and insulin resistance. Eur J Endocrinol 2004; 151 Suppl 3:U131-9.

32. Fonseca MJM. Índice de massa corporal de funcionários públicos do Rio de Janeiro: validade da informação referida e associação com a posição socioeconômica no estudo Pró-Saúde [Tese de Doutorado]. Rio de Janeiro: Escola Nacional de Saúde Pública, Fundação Oswaldo Cruz; 2003.

33. Lucas A, Fewtrell MS, Cole TJ. Fetal origins of adult disease-the hypothesis revisited. BMJ 1999; 319:245-9.

34. Hoyle R. The structural equation modeling approach. In: Hoyle R, editor. Structural equation modeling: concepts, issues and applications. Thousand Oaks: Sage Publications; 1995. p. 1-15.

35. Twisk JWR. Applied longitudinal data analysis for epidemiology: a practical guide. Cambridge: Cambridge University Press; 2003.

36. Amigo H. Obesidad en el niño en América Latina: situación, criterios de diagnóstico y desafíos. Cad Saúde Pública 2003; 19 Suppl 1:S163-70.

37. Cole TJ, Bellizzi MC, Flegal KM, Dietz WH. Establishing a standard definition for child overweight and obesity worldwide: international survey. BMJ 2000; 320:1240-3.

Recebido em 02/Set/2005

Versão final reapresentada em 14/Mar/2006 Aprovado em 12/Jul/2006 